\title{
On the Examination of Temperature-Dependent Possible Current-Conduction Mechanisms of Au/(nanocarbon-PVP)/n-Si Schottky Barrier Diodes in Wide Range of Voltage
}

Ömer SEVGiLi ( $\square$ omersevgili06@gmail.com)

Bingol Universitesi https://orcid.org/0000-0003-1740-1444

\section{Original Research}

Keywords: Current-voltage-temperture (I-V-T) characteristics, Current-transport mechanisms, Origin of Barrier inhomogeneity, Energy and temperature dependent profiles of surface states

Posted Date: February 9th, 2021

DOI: https://doi.org/10.21203/rs.3.rs-194859/v1

License: (c) (1) This work is licensed under a Creative Commons Attribution 4.0 International License. Read Full License

Version of Record: A version of this preprint was published at Journal of Materials Science: Materials in Electronics on March 15th, 2021. See the published version at https://doi.org/10.1007/s10854-02105669-0. 


\title{
On the Examination of Temperature-Dependent Possible Current-Conduction Mechanisms of Au/(nanocarbon-PVP)/n-Si Schottky Barrier Diodes in Wide Range of Voltage
}

\author{
Ömer Sevgili ${ }^{a}$ \\ ${ }^{a}$ Vocational School of Health Services, Bingöl University, Bingöl, Turkey
}

\begin{abstract}
$\mathrm{Au} /($ nanocarbon-PVP)/n-Si SDs were fabricated and their current-conduction mechanisms (CCMs) have been examined in elaborative by utilizing current-voltage (I-V) characteristics in temperature range of $60-340 \mathrm{~K}$ at $( \pm 3 \mathrm{~V})$ ranges. The values of ideality factor $(\mathrm{n})$ and zero-bias barrier height $\left(\Phi_{\mathrm{Bo}}\right)$ determined from the linear-part of semilogarithmic forward bias $\mathrm{I}_{\mathrm{F}}-\mathrm{V}_{\mathrm{F}}$ properties based on Thermionic-Emission (TE) theory revealed that decrease in $\Phi_{\mathrm{Bo}}$ and increase in $\mathrm{n}$ with deccreasing temperature. Additionally, Richardson constant $\left(\mathrm{A}^{*}\right)$ value was found several orders lower than its theoretical value. The values of $\Phi_{\mathrm{Bo}}$ and $\mathrm{n}$ changed from $0.173 \mathrm{eV}$ to $0.837 \mathrm{eV}$ and 6.60 to 2.85 with increasing temperature from $60 \mathrm{~K}$ to $340 \mathrm{~K}$. This positive temperature-coefficient $(\alpha)$ of $\Phi_{\text {Во }}$ is inagreement with the bandgap of semiconductor or barrier height $(\mathrm{BH})$ for the ideal diode. The calculated higher value of $\mathrm{n}$ at low temperatures was attributed to the inhomogeneities of $\mathrm{BH}$ rather than the interlayer, surface-states $\left(\mathrm{N}_{\mathrm{ss}}\right)$, and imageforce lowering. With lowing temperatures, CCMs may be governed by tunneling over the lower barriers, via $\mathrm{N}_{\mathrm{ss}}$, and generation recombination (GR), as well as $\mathrm{TE}$ and hence a complete description of CCM and understanding of the formation $\mathrm{BH}$, remain a compelling problem. $\mathrm{N}_{\mathrm{ss}}{ }^{-}$ $\left(\mathrm{E}_{\mathrm{c}}-\mathrm{E}_{\mathrm{ss}}\right)$ profile was also obtained from $\mathrm{I}_{\mathrm{F}}-\mathrm{V}_{\mathrm{F}}$ data for each temperature.
\end{abstract}

Keywords: Current-voltage-temperture (I-V-T) characteristics; Current-transport mechanisms; Origin of Barrier inhomogeneity; Energy and temperature dependent profiles of surface states

Corresponding authors: Ömer SEVGILİ : omersevgili06@gmail.com 


\section{Introduction}

In the metal-semiconductor (MS) structures, the used an interlayer such as insulator/oxide, organic or composite interlayers between metal (M) and semiconductor (S) is important to increase the quality/performance of them because of it may be prevented an inter-diffusion between the metal and interlayer by isolating the metal from the smiconductgor and regulate the current conduction [1-5]. Therefore, nowadays, both scientific and technical problems of the metal-semiconductor (MS) type Schottky barrier diodes (SDs) with and without interlayer and solar cells (SCs) are appropriate to the increase in the performance of them and to reduce in the cost and easy fabrication methods [1-4]. Morevcer, it is an essential demand to improve the costeffective devices with high performance inside of conventional MS and MIS type SDs and SCs. However, the performance of these devices is decreased under real operating conditions when compared ideal case, especially with lowing temperatures. In other words, with lowing temperature the probable current-conduction mechanisms (CCMs) become more complex due to deviation from the standard thermionic-emission (TE) theory [5-9].

Usually, the observed very lower value of $\mathrm{A}^{*}$ as experimentaly indicated that the spatial inhomogeneous of $\mathrm{BH}$ and potential fluctuations at the interface which is containt many low and high barrier areas or patches and hence the current transport across diode would flow preferentially through these lower barriers and leads to an increase in deality factor. Therefore, a perfect description of CCMs through barrier and comprehension of the nature of $\mathrm{BH}$ still at $\mathrm{M} / \mathrm{S}$ interface remain a compelling problem. Under room temperatures, in these structures, a number of CCMs for instance TE, field/thermionic-field emission (FE/TFE), multistep tunneling (MT) via $\mathrm{N}_{\mathrm{ss}}$, and Gaussian distribution (GD) of BHs compete and one of them may dominate over the others in a particular temperature and bias voltage region. In addition, there may be simultaneous contributions from two or more CCMs. However, TFE and FE are effective only with lowing temperatures and high doping concentrations in semiconductors [3,9-13].

In practice, utilizing the TE theory, the zero biased $\mathrm{BH}\left(\Phi_{\mathrm{Bo}}\right)$ values, understood from the linear portions of semilogarithmic I-V curves in the forward-biased region, increase by increasing temperature, while the $\mathrm{n}$ values decrease and the traditional Richardson graph deviates considerably from linearity under room or with lowing temperatures. When temperature becomes decrease, charge carriers can easily pass over the existence of patches of lower barriers at around mean $\mathrm{BH}$ and so leads to a large ideality factor, but as temperature increase these lower barriers and patches are offset by the much greater area of the uniform region, consequently, most current flows through the uniform region. In addition, the magnitude 
of the $\mathrm{A}^{*}$ obtained from the Richardson plot can be some orders less than the theoretical value. It is well known that the increase in $\mathrm{BH}$ with increasing temperature does not correspond to the prohibited band gap negative temperature of the semiconductors.

The inconsistency observed between experimental and theoretical values is related to many magnitudes. For example, surface fabrication may include natural or a layer or both thickness and homogeneity, BH homogeneity at the M/S interface, voltage, surface temperature, eg homogeneity; surface conditions of these devices $\left(\mathrm{N}_{\mathrm{ss}}\right)$, series and shunt-resistances $\left(\mathrm{R}_{\mathrm{s}}, \mathrm{R}_{\mathrm{sh}}\right)$ [12-18]. When observed experimentally, the low $A^{*}$ value shows that the effective area is actually much smaller than the diode area [19-23]. Therefore, analysis of CCMs in the temperature amplitude and applied pre-voltage voltage can ensure us with a lot of information, on the other hand, only in narrow or narow-temperature range $\mathrm{BH}$ does not give knowledge about the nature of the CCMs and the effect of the interlayer.

The purpose of this working is to produce Au/(nanocarbon-PVP)/n-Si (MPS) SDs and investigate the probable CCMs by utilizing the I-V-T properties in a wide range of temperature (60-340 K) to get more acknowledge on the nature of $\mathrm{BH}, \mathrm{CCMs}$ and effect of interlayer. The energy-dependent profiles of the surface-states ( $\left.N_{s s} v s E_{c}-E_{s s}\right)$ were found in consideration of voltage-dependent $\mathrm{BH}$ and $\mathrm{n}$ for each temperature. We observed that $\Phi_{\text {Во }}$ magnitude increases with increasing temperature, $\mathrm{n}$ decreases, this behavior is clearly clarified by TE mechanism which is a GD of $\mathrm{BH}$ rather than other CCMs such as TFE and FE.

\section{Experimental Procedures}

Carbon nanoparticles can be purchased from the market with a purity of $99.9 \%$ was purchased from Xuzhou Hongwu Co. (China). SEM and XRD analyses were carried out on the nanocarbon powders to characterize this as-received material. In this working, $\mathrm{Au} /$ (nanocarbonPVP)/n-Si (MPS) SDs were performed on phosphor doped (n-Si) substrate with (100) float zone, $300 \mu \mathrm{m}$ thickness, and $1 \Omega \mathrm{cm}$ resistivity. Firstly, the substrate went through ultrasonic acetone, alcohol, deionize (DI) water with $18 \mathrm{M} \Omega . \mathrm{cm}$ resistivity cleaning and a dilute HF dip in the ultrasonic bath to remove oxide produced on the surface. After that, it was cleaned in $\mathrm{H}_{2} \mathrm{O}$, $\mathrm{H}_{2} \mathrm{O}_{2}$, and $\mathrm{NH}_{4} \mathrm{OH}(3: 1: 1)$ solution at $70{ }^{\circ} \mathrm{C}$ and then rinsed with high-pure deionize water at about 10 minutes. Immediately it was dried with dry $\mathrm{N}_{2}$ gas and subsequently was placed inside the deposition chamber to perform ohmic contact. After that high-pure gold (99.999\%) with 150 $\mathrm{nm}$ thick was thermally evaporated on the whole backside of the substrate at $10^{-6}$ Torr, to perform a good ohmic contact. The prepared (nanocarbon-PVP) composite was grown on the front of nSi substrate by spin coating method. Finally, circular dots with $1 \mathrm{~mm}$ diameter and $150 \mathrm{~nm}$ thick 
high-pure of Au rectifying contacts were produced on the (nanocarbon-PVP) composite through a metal- shadow mask in the high-vacuum thermal evaporation system at $10^{-6}$ Torr. In order to perform the forward and reverse bias I-V measurements of the SDs, they were fixed on a $\mathrm{Cu}$ holder by silver paste and electrode connections were made by silver-coated thin $\mathrm{Cu}$ wires. Morphological and structural namocabon-PVP composite were performed using Scanning Electron Microscope (SEM), XRD analysis was recorded by Philips X'Pert, X-ray diffractometer using $\mathrm{Cu} \mathrm{K} \alpha$ radiation (wavelength=1.54056 $\AA$ ), I-V measurements were performed on a Janis VPF-475 cryostat temperature controller utilizing a Keithley $2400 \mathrm{I}-\mathrm{V}$ source meter. All measurements were made utilizing a microcomputer via an IEEE-488 ac/dc converter board.

\section{Experimental Results and Discussions}

The XRD pattern of the sheetlike nanocarbon is shown in Fig. 1. All the diffraction peaks at $2 \theta: 26.5^{\circ}, 43.0^{\circ}, 54.6^{\circ}$, and $77.8^{\circ}$ can be indexed as the (002), (100), (004) and (110) plans of nanocarbon. The strong diffraction peaks at $2 \theta=26.5^{\circ}$ could be ascribed to the $\left(\begin{array}{lll}0 & 0 & 2\end{array}\right)$ reflection and (1 0$)$ band of nanocarbon. The mean crystal size of nanostructures was obtained $15 \mathrm{~nm}$ by Scherrer formula.

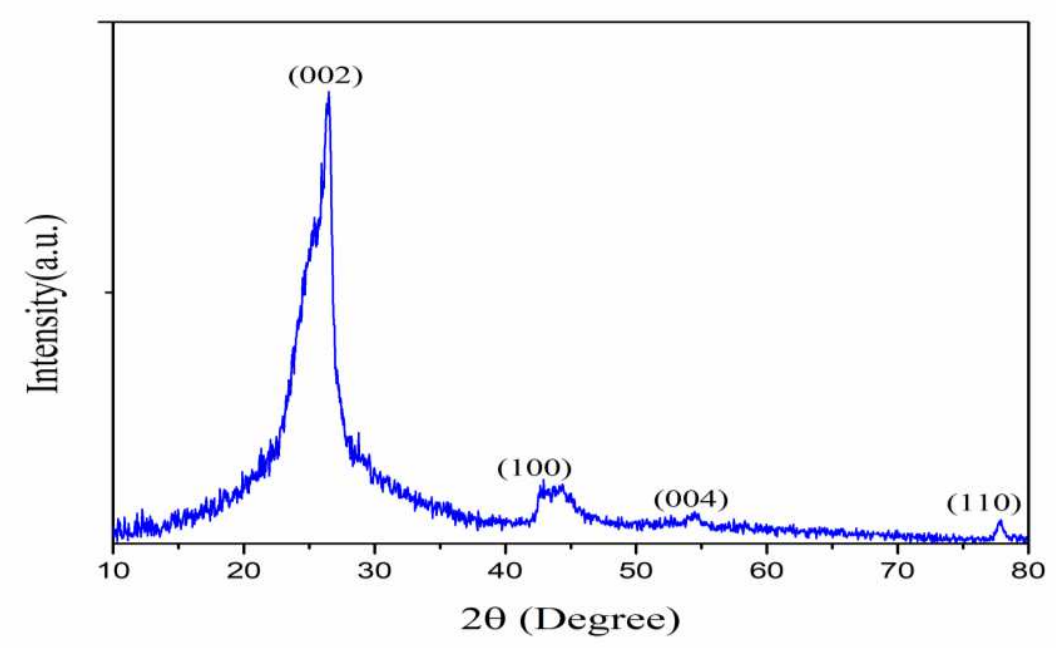

Fig. 1. The XRD patterns of nanocarbon.

Figure 2 shows the representative SEM images of sheetlike nanocarbon at different magnification. While the average-size of the clusters was found about micrometer, the meansize of the nanoparticles wasfound less than $50 \mathrm{~nm}$. 

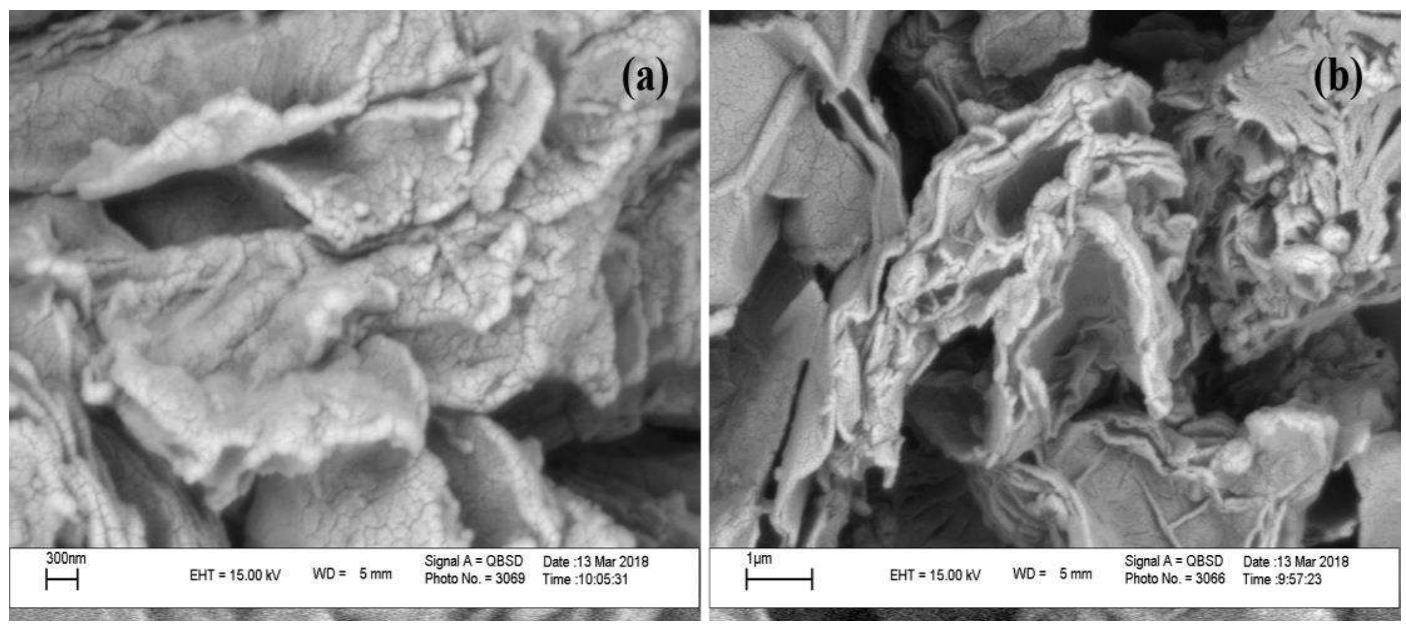

Fig. 2. SEM images of nanocarbon: a) $50 \mathrm{kx}$, b) $30 \mathrm{kx}$.

The $\ln (\mathrm{I})$ vs V plot s of the Au/(nanocarbon-PVP)/n-Si (MPS) type SD was given in Fig. 3 in the wide temperature range (60-340 K). In this figure, the forward bias $\ln (\mathrm{I})$ vs $\mathrm{V}$ plot has a good straight line with different slopes and then deviated from the linearity at enough high forward-bias voltages due to the existence of $\mathrm{R}_{\mathrm{s}}$ and (nanocarbon-PVP) interlayer for each temperature. The effect of $R_{s}$ in the linear region of $\operatorname{Ln}(\mathrm{I})$ vs $\mathrm{V}$ may be neglected low. On the other hand, the current in the reverse bias regime is almost independent from the bias voltage.

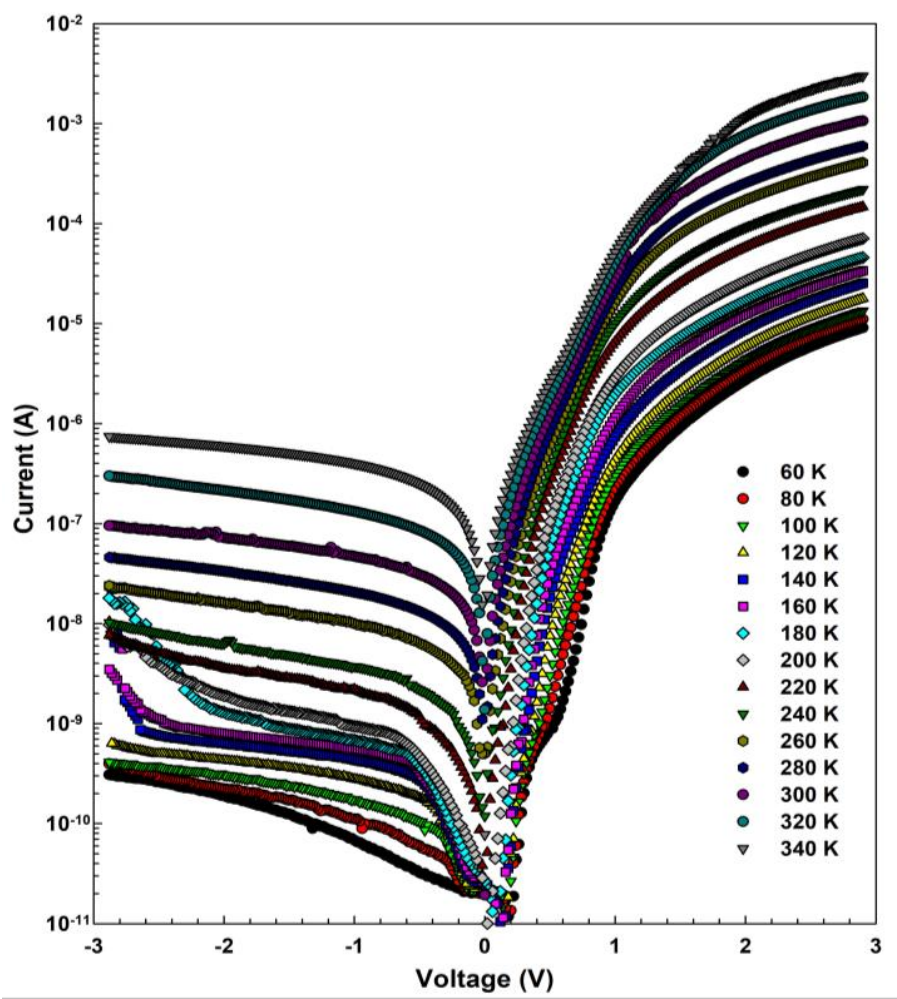

Fig. 3. The I-V-T characteristics of the Au/(nanocarbon-PVP)/n-Si SD. 
On the other hand, the valoe of current at the forward bis voltage increases with increasing voltage as almost exponentially and starts deviated from the linearity for enough high-forward bias voltage due to the effect of $\mathrm{R}_{\mathrm{s}}$ and polymer interlayer for each temperature. Such behavior of the current with bias voltage is known as "rectifying rate" $\left(R R=I_{F} / I_{R}\right)$ and it decrease with increasing temperature. Since the MS and MIS type SDs have a Rs, the connection with I and $\mathrm{V}$ for them based on standard TE theory $(\mathrm{V} \geq 3 \mathrm{kT} / \mathrm{q})$ is given as $[14,15]$ :

$$
I=A A^{*} T^{2} \exp \left(-\frac{q}{k T} \Phi_{B o}\right)\left[\exp \left(\frac{q\left(V-I R_{s}\right)}{n k T}\right)-1\right]
$$

In Eq. 1; $\mathrm{V}$ is the applied voltage on the diode and the other units are known in the literature [24-26]. The expressions in front of brackets is called as the reverse-saturation current $\left(\mathrm{I}_{0}\right)$ which is obtained from the interception of the linear parts $\ln (\mathrm{I})$ vs $\mathrm{V}$ plot. Thus, the value of zero-bias $\mathrm{BH}\left(\Phi_{\mathrm{Bo}}\right)$ can be calculated from the expression $\left(\mathrm{I}_{\mathrm{o}}\right)$ as following equality for each temperature.

$$
\Phi_{B o}=\frac{k T}{q} \operatorname{Ln}\left(\frac{A A^{*} T^{2}}{I_{0}}\right)
$$

The other an important magnitude of SDs is the ideality factor (n) which is more effective in the performance by controlling on the CCMs through interfaces and it can be also obtained from the slope of $\ln (\mathrm{I})$ vs $\mathrm{V}$ plot as given follow [15]:

$$
n=\frac{q}{k T}\left(\frac{d V}{d(\ln I)}\right)=1+\frac{\delta_{i}}{\varepsilon_{i}}\left[\frac{\varepsilon_{s}}{W_{D}}+q N_{s s}\right]
$$

where the $\varepsilon_{s}$ is the dielectric constant of semiconductor,and the other units are known in the literature [24-26]. Thus, the obtained experimental values of these main electrical magnitudes $\left(\mathrm{I}_{\mathrm{o}}, \mathrm{n}, \Phi_{\mathrm{Bo}}\right)$ of the Au/(nanocarbon-PVP)/n-Si (MPS) type SD are shown in Table 1. As shown both in Table 1 and Fig. 4, values of main electrical magnitudes $\left(I_{o}, n, \Phi_{\text {Bo }}\right)$ are strong function of temperature and changed from the $1.14 \times 10^{-12} \mathrm{~A}, 16.60$, and $0.173 \mathrm{eV}$ for $60 \mathrm{~K}$ to $4.05 \times 10^{-8} \mathrm{~A}$, 2.85, and $0.837 \mathrm{eV}$ for $340 \mathrm{~K}$. The obtained values of $\mathrm{n}$, particularly with lowing temperatures, are quite higher than unity and they can be explained a spatial barrier inhomogeneities at M/S interface rather than (nanocarbon-PVP) organic interlayer, $\mathrm{W}_{\mathrm{D}}$ or non-uniform doped donor atoms $\left(\mathrm{N}_{\mathrm{D}}\right)$, and interface recombination. Additionally, in Table 1 and Fig. 4, while $\mathrm{n}$ increases with decreasing temperature as exponentially, $\Phi_{\text {Во }}$ decreases as exponentially. Such alteration in $\Phi_{\text {Bo }}$ with temperature is disagreement with the negative temperature coefficient $(\alpha=\mathrm{dEg} / \mathrm{dT}=$ - 
$4.73 \times 10^{-4} \mathrm{eV} / \mathrm{K}$ for $\mathrm{Si}$ ) of the bandgap of Si. According to Tung [22], this state of $\mathrm{BH}$ with temperature is the result of treated system of discrete regions or "patches"' of low BHs embedded in a higher background uniform $\mathrm{BH}$.

Table. 1. The extracted temperature-dependent some experimental values from the forward bias I-V characteristics for the Au/(nanocarbon-PVP)/n-Si SD.

\begin{tabular}{|c|c|c|c|c|c|c|c|}
\hline $\begin{array}{c}\mathbf{T} \\
(\mathbf{K})\end{array}$ & $\begin{array}{c}\mathbf{I}_{\mathbf{0}} \\
(\mathbf{A})\end{array}$ & $\mathbf{n}$ & $\begin{array}{c}\boldsymbol{\Phi}_{\mathbf{B o}} \\
(\mathbf{e V})\end{array}$ & $\begin{array}{c}\boldsymbol{\Phi}_{\text {Bef }} \\
(\mathbf{e V})\end{array}$ & $\begin{array}{c}\mathbf{n T} \\
(\mathbf{K})\end{array}$ & $\begin{array}{c}\mathbf{R}_{\mathbf{s}}(\mathbf{a t ~ 3 V}) \\
(\mathbf{k} \boldsymbol{\Omega})\end{array}$ & $\begin{array}{c}\mathbf{R}_{\mathbf{s h}}(\mathbf{a t ~ - 3 ~ V}) \\
(\mathbf{M} \boldsymbol{\Omega})\end{array}$ \\
\hline 60 & $1.14 \times 10^{-12}$ & 16.60 & 0.173 & 1.068 & 1026 & 292.2 & $9.6 \times 10^{3}$ \\
\hline 80 & $4.28 \times 10^{-12}$ & 11.01 & 0.240 & 1.050 & 993 & 241.5 & $8.5 \times 10^{3}$ \\
\hline 100 & $5.13 \times 10^{-12}$ & 8.47 & 0.303 & 1.029 & 914 & 198.9 & $6.8 \times 10^{3}$ \\
\hline 120 & $5.64 \times 10^{-12}$ & 6.81 & 0.366 & 1.011 & 839 & 151.8 & $5.0 \times 10^{3}$ \\
\hline 140 & $1.27 \times 10^{-11}$ & 5.70 & 0.421 & 0.953 & 773 & 107.8 & $3.3 \times 10^{3}$ \\
\hline 160 & $1.36 \times 10^{-11}$ & 4.79 & 0.484 & 0.928 & 731 & 83.0 & $2.3 \times 10^{3}$ \\
\hline 180 & $3.12 \times 10^{-11}$ & 4.24 & 0.535 & 0.885 & 756 & 61.3 & $9.4 \times 10^{2}$ \\
\hline 200 & $7.17 \times 10^{-11}$ & 3.93 & 0.584 & 0.870 & 786 & 39.9 & $6.5 \times 10^{2}$ \\
\hline 220 & $3.03 \times 10^{-10}$ & 3.75 & 0.618 & 0.823 & 817 & 19.0 & $5.0 \times 10^{2}$ \\
\hline 240 & $5.97 \times 10^{-10}$ & 3.58 & 0.664 & 0.820 & 869 & 12.7 & $3.1 \times 10^{2}$ \\
\hline 260 & $1.93 \times 10^{-09}$ & 3.43 & 0.696 & 0.773 & 892 & 6.9 & $1.2 \times 10^{2}$ \\
\hline 280 & $3.90 \times 10^{-09}$ & 3.34 & 0.737 & 0.766 & 935 & 4.7 & $6.2 \times 10^{1}$ \\
\hline 300 & $8.11 \times 10^{-09}$ & 3.19 & 0.774 & 0.735 & 960 & 2.7 & $3.0 \times 10^{1}$ \\
\hline 320 & $1.59 \times 10^{-08}$ & 2.99 & 0.811 & 0.691 & 928 & 1.6 & $9.6 \times 10^{0}$ \\
\hline 340 & $4.05 \times 10^{-8}$ & 2.85 & 0.837 & 0.631 & 945 & 1.0 & $3.7 \times 10^{0}$ \\
\hline
\end{tabular}

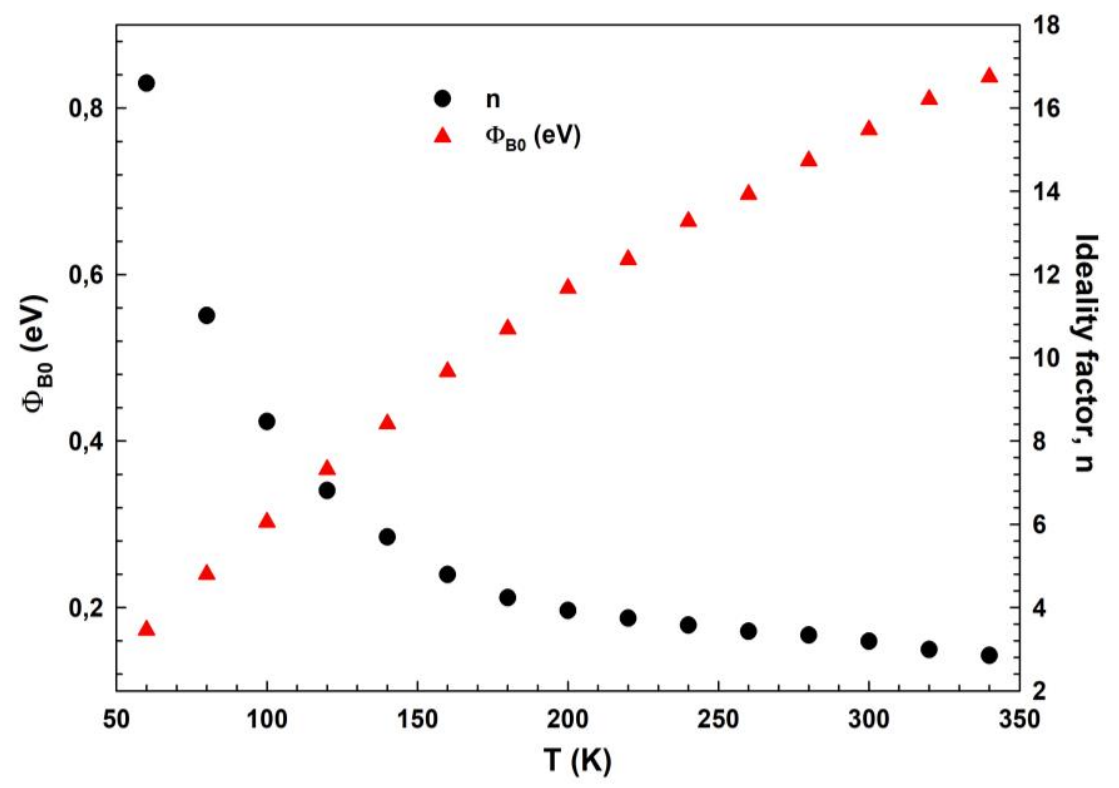

Fig. 4. The changes in $\mathrm{BH}$ and $\mathrm{n}$ with temperature in $\mathrm{Au} /($ nanocarbon-PVP)/n-Si SD.

The structure resistance $\left(\mathrm{R}_{\mathrm{i}}\right)$ of the $\mathrm{Au} /($ nanocarbon-PVP)/n-Si SD is a function of applied voltage $\left(\mathrm{V}_{\mathrm{i}}\right)$, but as shown in Fig. 5 the real values of $\mathrm{R}_{\mathrm{s}}$ is corresponds to enough high forward 
while shunt resistance $\left(\mathrm{R}_{\mathrm{sh}}\right)$ is corresponds to enough low reverse voltages. The semilogarithmic I-V plots (Fig. 3) deviation from the linearity towards to higher bias voltages because of the effect of $R_{s}$ for each temperature and hence both the $R_{s}$ and $R_{s h}$ values were calculated as a function of temperature by utilizing Ohm's Law $\left(\mathrm{R}_{\mathrm{i}}=\mathrm{dV} \mathrm{V} / \mathrm{dI}_{\mathrm{i}}\right)$ at $\pm 3 \mathrm{~V}$, respectively, and were also shown in Table 1. Additionally, Ohm's law provides quick results for the calculation of $\mathrm{R}_{\mathrm{s}}$ and Rsh of MS and MIS type SDs; therefore, it was usually utilized for extraction of these two resistances values from the $\mathrm{I}-\mathrm{V}$ data.In Table 1 and Fig.5, both the value of $\mathrm{R}_{\mathrm{s}}$ and $\mathrm{R}_{\text {sh }}$ are strong functions of temperature and decrease with increasing temperature almost as exponentially. Such decreasing behavior in the $R_{s}$ and $R_{s h}$ can be attributed to the increase in the free carrier concentrations because of decreasing of forbidden bandgap of Si and gained thermal energy $[15,20,23]$.

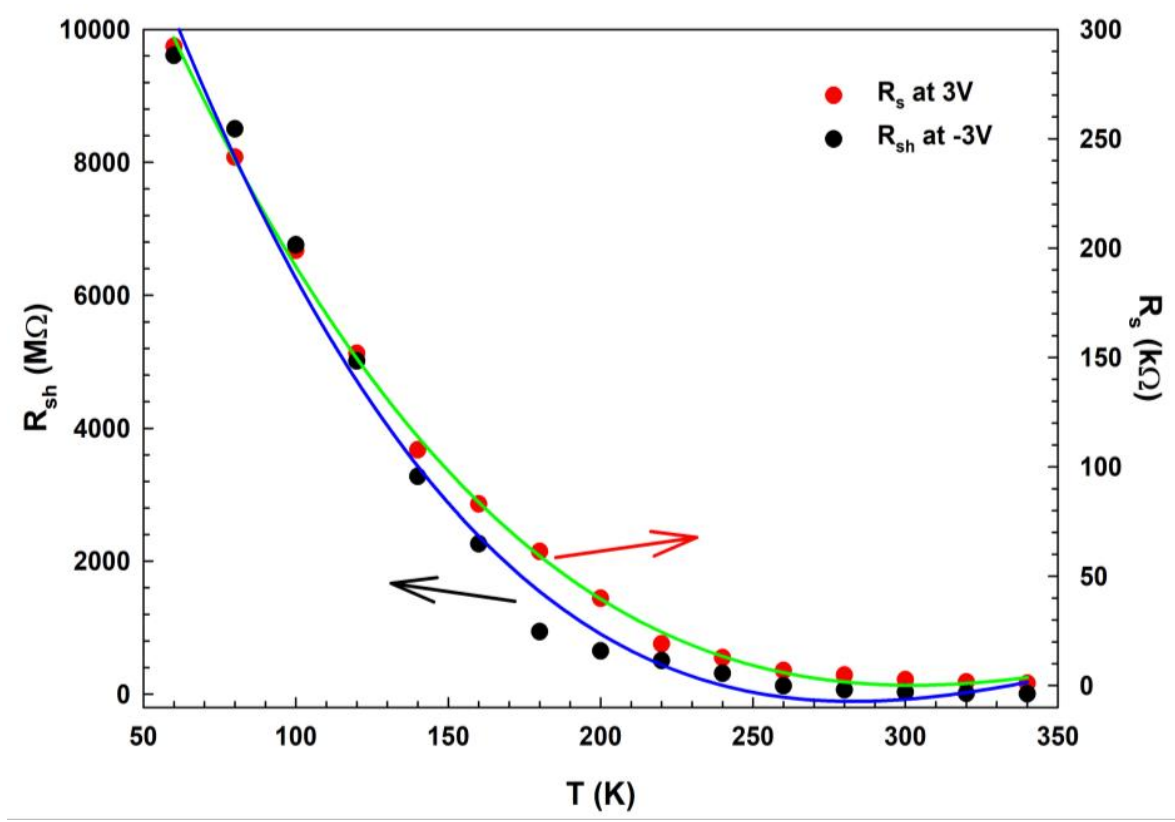

Fig. 5. The changes in $R_{s}$ and $R_{s h}$ with temperature in $A u /($ nanocarbon-PVP)/n-Si SD.

The conventional Richardson plots give also more information on the spatial distribution of both activation energy $\left(\mathrm{E}_{\mathrm{a}}\right)$ and $\mathrm{BH}$ or Richardson constant. Therefore, the $\ln \left(\mathrm{I}_{\mathrm{o}} / \mathrm{T}^{2}\right) \mathrm{vs} \mathrm{q} / \mathrm{kT}$ was drawn and is shown in Fig. 6. In Fig 6, the plotted conventional Richardson/Arrhenius plot of the $\mathrm{Au} /($ nanocarbon-PVP)/n-Si SD has a straight line at intermediate and high temperatures (160-340 K) but starts to deviate from linearity at with lowing temperatures (60-140 K). The $\mathrm{E}_{\mathrm{a}}$ and $\mathrm{A}^{*}$ values were found as $0.172 \mathrm{eV}$ and $6.77 \times 10^{-11} \mathrm{~A} / \mathrm{cm}^{2} \mathrm{~K}^{2}$ for the $\mathrm{Au} /($ nanocarbon-PVP)/nSi SD by utilizing Eq. 4. 
$\operatorname{Ln}\left(\frac{I_{o}}{T^{2}}\right)=\ln \left(A A^{*}\right)-\frac{q \Phi_{B o}}{k T}$

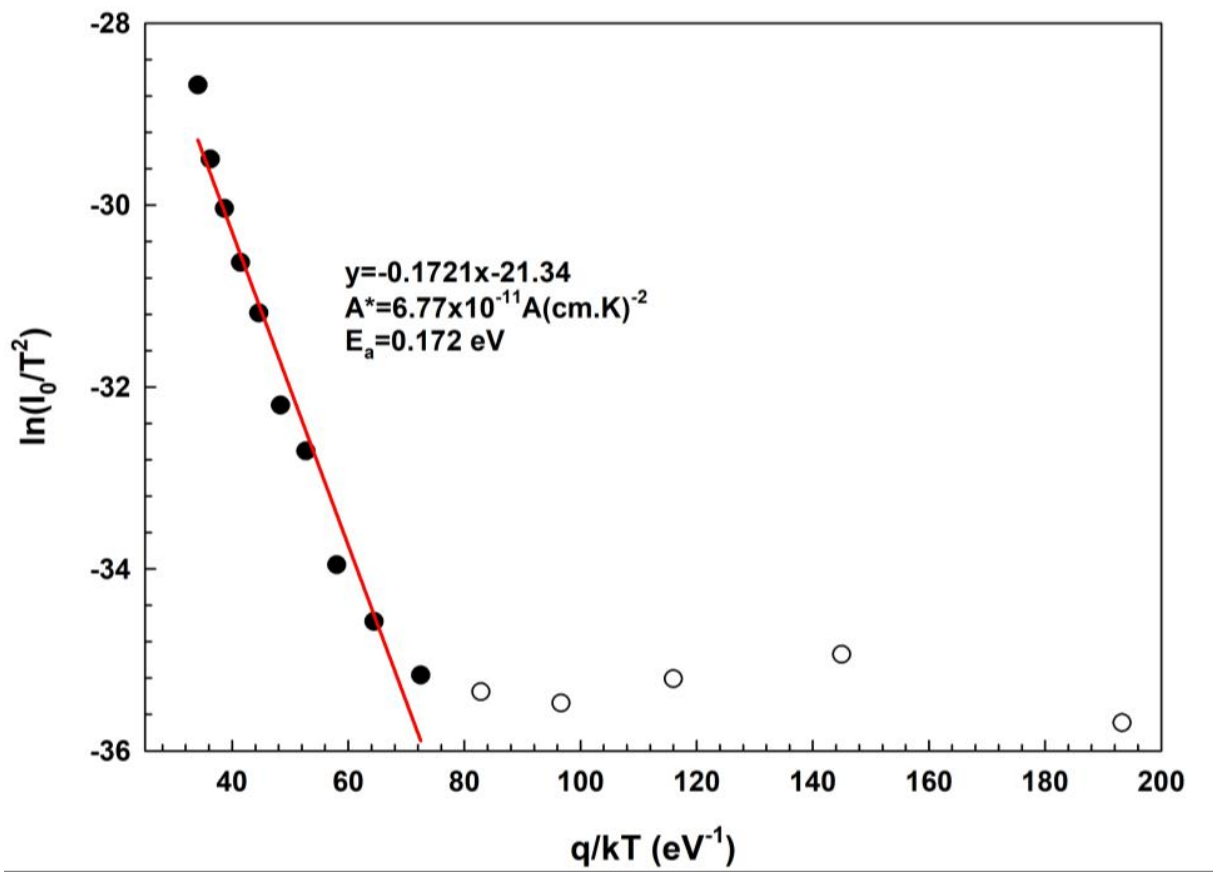

Fig. 6. The conventional Richardson/Arrhenius plot of the Au/(nanocarbon-PVP)/n-Si SD.

The obtained experimental value of $A^{*}$ is very-very lower than the theoretical value (112 $\mathrm{A} / \mathrm{cm}^{2} \mathrm{~K}^{2}$ for $\mathrm{n}-\mathrm{Si}$ ). The obtained value of $\mathrm{E}_{\mathrm{a}}$ is also considerably lower than the mid-gap of Si. The obtained low value of $A^{*}$ may be affected by lateral inhomogeneity of the $\mathrm{BH}$ [7,27]. These discrepancies between their experimental and theoretical values have already been reported by many researchers and are often attributed to the spatial inhomogeneity of $\mathrm{BH}$ and potential fluctuations involving many low BHs or patches at the M/S interface $[1,2,27-30]$. In this case, electrons can easy pass over these lower BHs even at low temperatures and so leads an increase in the ideality factor. But, at enough high temperatures, these charges gain enough energy to surpass the higher barriers, as a result, the apparent barrier height $\left(\Phi_{\mathrm{ap}}=\Phi_{\mathrm{Bo}}\right)$ increases with the increasing temperature [28-31].

Because the semiconductor has atoms with high doping concentrations, electrons can be tunneled from semiconductor to metal, and this process is known as a tunnel of quantum mechanics involving thermionic field and field emission (TFE, FE) CTMs [11-13]. Tunneling the mechanism can only be dominated at low temperatures and high doping concentrations, and in this case, n.T becomes almost constant. In addition, MS or MIS type SDs have many surface states/traps $\left(\mathrm{N}_{\mathrm{ss}}\right)$ and dislocation between interlayer and semiconductor, current conduction may 
be governed via these traps and dislocation. For the tunneling type CTMs, the slope of $\ln (\mathrm{I})$ vs $\mathrm{V}$ plot is usually independent of temperature. In order to detrmine either or not dominate the tunneling and $\mathrm{T}_{\mathrm{o}}$ anomaly, the theoretically (for $\mathrm{n}=1$ ) and experimental $\mathrm{nkT} / \mathrm{q}$ vs $\mathrm{kT} / \mathrm{q}$ plots were drawn and in Fig. 7. In Fig. 7, the FE and TFE may be dominated as partly because of the values of (n.T) are almost constant or independent from temperature.

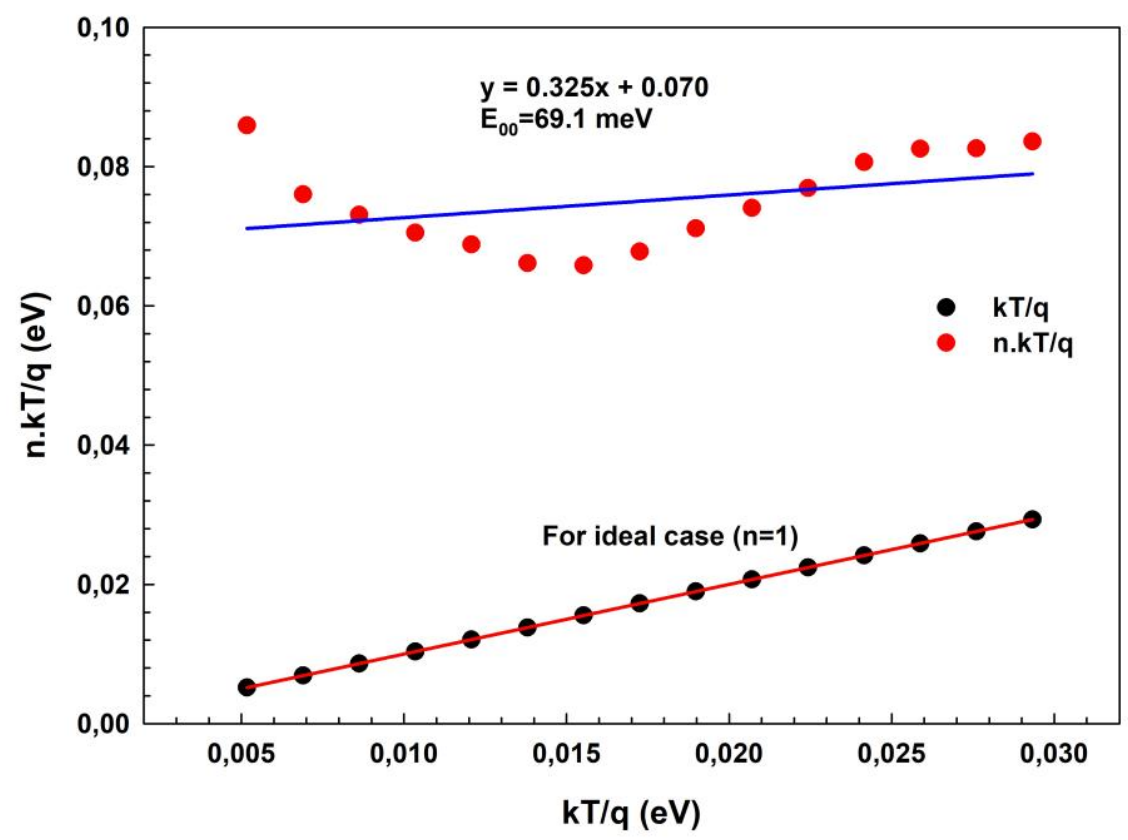

Fig. 7. The nkT/q vs kT/q plot of the Au/(nanocarbon-PVP)/n-Si SD.

Additionally, both the FE and TFE type CTMs are also required an alteration in the tunneling current magnitude with temperature as $[3,11,13]$ :

$n_{\text {tun }}=\left(\frac{E_{00}}{k T}\right) \cdot \operatorname{coth}\left(\frac{E_{00}}{k T}\right)$ with $\quad E_{00}=\frac{h}{4 \pi}\left(\frac{N_{D}}{m_{e} \times \varepsilon_{s}}\right)^{0.5}$

In Eq. 5, the $\mathrm{me}_{\mathrm{e}}{ }^{*}$ is the effective mass of electrons and $\varepsilon_{\mathrm{s}}$ is dielectric of the Si. The value of $\mathrm{E}_{\mathrm{oo}}$ was found as $0.36 \mathrm{meV}$ by using $\mathrm{m}_{\mathrm{e}}{ }^{*} \sim \mathrm{m}_{\mathrm{o}}\left(=9.1 \times 10^{-31} \mathrm{~kg}\right)$, dielectric of $\mathrm{Si} \varepsilon_{\mathrm{s}}\left(=11.8 \varepsilon_{\mathrm{o}}\right)$, dielectric of vacuum $\left(8.85 \times 10^{-12} \mathrm{~F} / \mathrm{m}\right)$, and $\mathrm{N}_{\mathrm{D}}\left(=4.31 \times 10^{21} \mathrm{~m}^{-3}\right)$ supplied by the manufacturer. This experimental value of $\mathrm{E}_{\mathrm{oo}}$ is quite lower than the thermal energy $(=\mathrm{kT} / \mathrm{q})$ even at the measured at low temperature $(60 \mathrm{~K})$. This theoretical value of Eoo shows that FE and TFE theories are unlike mechanism in the whole temperature range of (60-340 K). But, as can be clearly seen in both Fig. 7 and Fig. 8, the value of $E_{o o}$ was found at about $69 \mathrm{meV}$ which is higher than $\mathrm{kT} / \mathrm{q}$ for all measured temperature. This is the second evidence the existence of FE and TFE. 


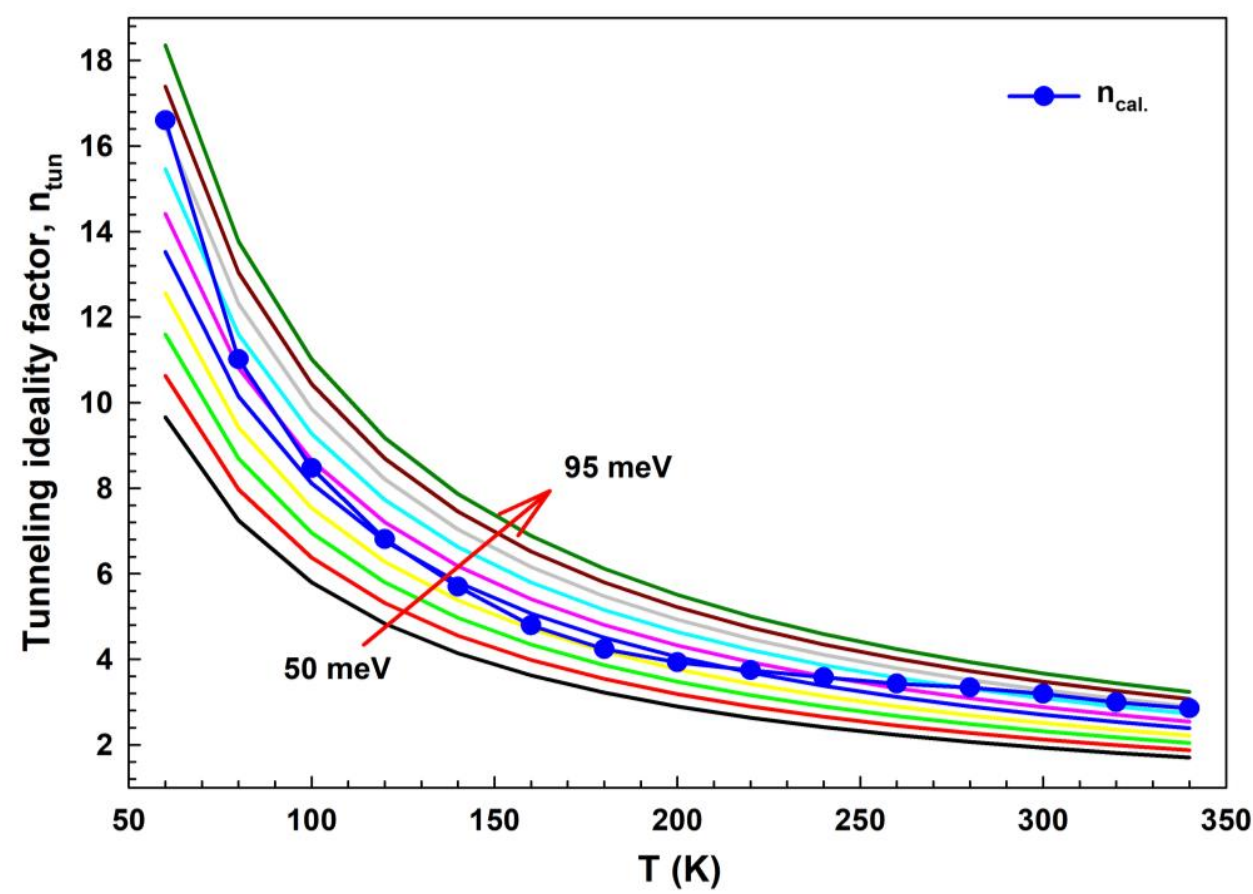

Fig. 8. The $\mathrm{n}_{\text {tun }} \mathrm{Vs} \mathrm{T}$ plot of the Au/(nanocarbon-PVP)/n-Si SD far various $\mathrm{E}_{\mathrm{oo}}$.

Mönch and co-authors used Tung's theory $[1,2,6]$ and obtained a good linear connection with $\bar{\Phi}_{\mathrm{Bo}}$ and $\mathrm{n}$. Thus, a significant decrease in $\bar{\Phi}_{\mathrm{Bo}}$ and an increase in $\mathrm{n}$ with lowing temperature explained the average GD in $\mathrm{BH}$ at the $\mathrm{M} / \mathrm{S}$ interface. Therefore, to obtain some evidence of

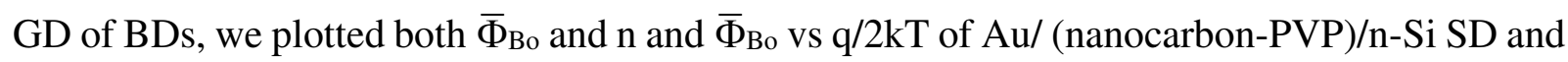

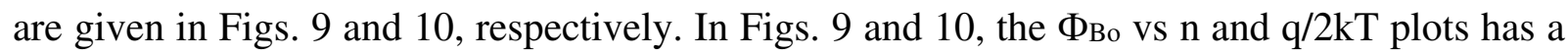
distinctive two linear regimes with different slopes. The extrapolation of the $\Phi_{\text {Bo }}$ vs $n$ plot to $\mathrm{n}=1$ was given a homogeneous $\mathrm{BH}$ as $1.176 \mathrm{eV}$ for moderate and high temperatures (160-340 $\mathrm{K})$ and $0.495 \mathrm{eV}$ for low temperature (60-140 K) region, respectively. 


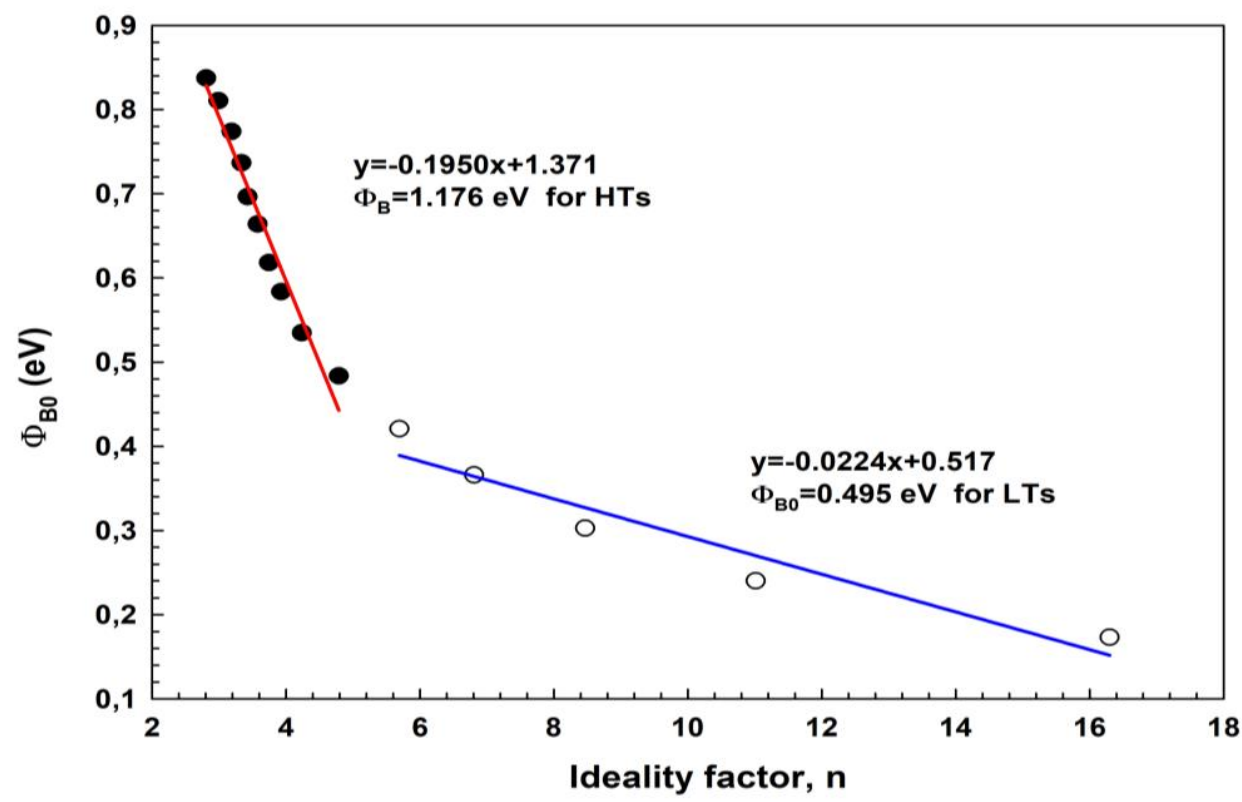

Fig. 9. Temperature-dependent $\Phi_{\text {во }}$ vs n plot of the Au/(nanocarbon-PVP)/n-Si SD.

The increase in $\Phi_{\text {Во }}$ and the decrease $\mathrm{n}$ as the temperature increases, the observed linear relationship between them can be expressed by the lateral distribution of $\mathrm{BH}$. In other words, it has a GD of the $\mathrm{BH}$ over the diode area with the mean value of $\mathrm{BH}\left(\bar{\Phi}_{\mathrm{Bo}}\right)$ and standard deviation $\left(\sigma_{\mathrm{so}}\right)[16,21-23,27-31]$. In this case, the GD of the $\mathrm{BH}\left(\Phi_{\mathrm{ap}}=\Phi_{\mathrm{Bo}}\right)$ and ideality factor $\left(\mathrm{n}=\mathrm{n}_{\mathrm{ap}}\right)$ with temperature is explained as the following relations:

$$
\begin{aligned}
& \Phi_{a p}=\bar{\Phi}_{B 0}-\frac{q \sigma_{s o}^{2}}{2 k T} \\
& n_{a p}^{-1}(T)-1=-\rho^{2}-q \times \frac{\rho^{3}}{2 k T}
\end{aligned}
$$

In Eq. 6, the temperature-dependent of $\sigma_{\text {so }}$ is can be neglected low. Otherwise, the quantities of $\rho_{2}$ and $\rho_{3}$ are the voltage deformation coefficients of $n$ which may be depended on temperature. Thus, the magnitudes of $\bar{\Phi}_{\text {Во }}$ and $\sigma_{\text {so }}$ were found from the intercept and slope of the $\Phi_{\text {во vs }}$ q/2kT plot (Fig.10) as $1.127 \mathrm{eV}$ and $0.136 \mathrm{~V}$ for moderate and high temperatures (160-340 K) and $0.578 \mathrm{eV}$ and $0.067 \mathrm{~V}$ for low temperatures (60-140 K), respectively. These magnitudes of $\sigma_{\text {so }}$ are not small compared with $\bar{\Phi}_{\text {Во }}$ and they show that a presence the barrier in-homogeneities at M/S interface. Similarly, $\rho_{2}$ and $\rho_{3}$ values were also found from the intercept and slope of the $\left(\mathrm{n}^{-1}-1\right)$ vs q/2kT plot (Fig. 11) as $-0.547 \mathrm{~V}$ and $-0.0068 \mathrm{~V}$ for moderate and high temperatures, and $-0.753 \mathrm{~V}$ and $-0.0021 \mathrm{~V}$ for low temperatures, respectively. The observed two linear regimes 
both in Figs. 10 and 11 are the results of existence of double GD of BHs in the SD area in the $\mathrm{Au} /\left(\right.$ nanocarbon-PVP)/n-Si SD and $\mathrm{N}_{\mathrm{ss}}$ at (nanocarbon-PVP)/n-Si interface [26,32-36]. Similar results on the barrier inhomogeneity and the effects of $\mathrm{N}_{\mathrm{ss}}, \mathrm{R}_{\mathrm{s}}$ and interlayer on the performance electrical caharacteristics were also reported in the literature in the recent years [26,37-42].

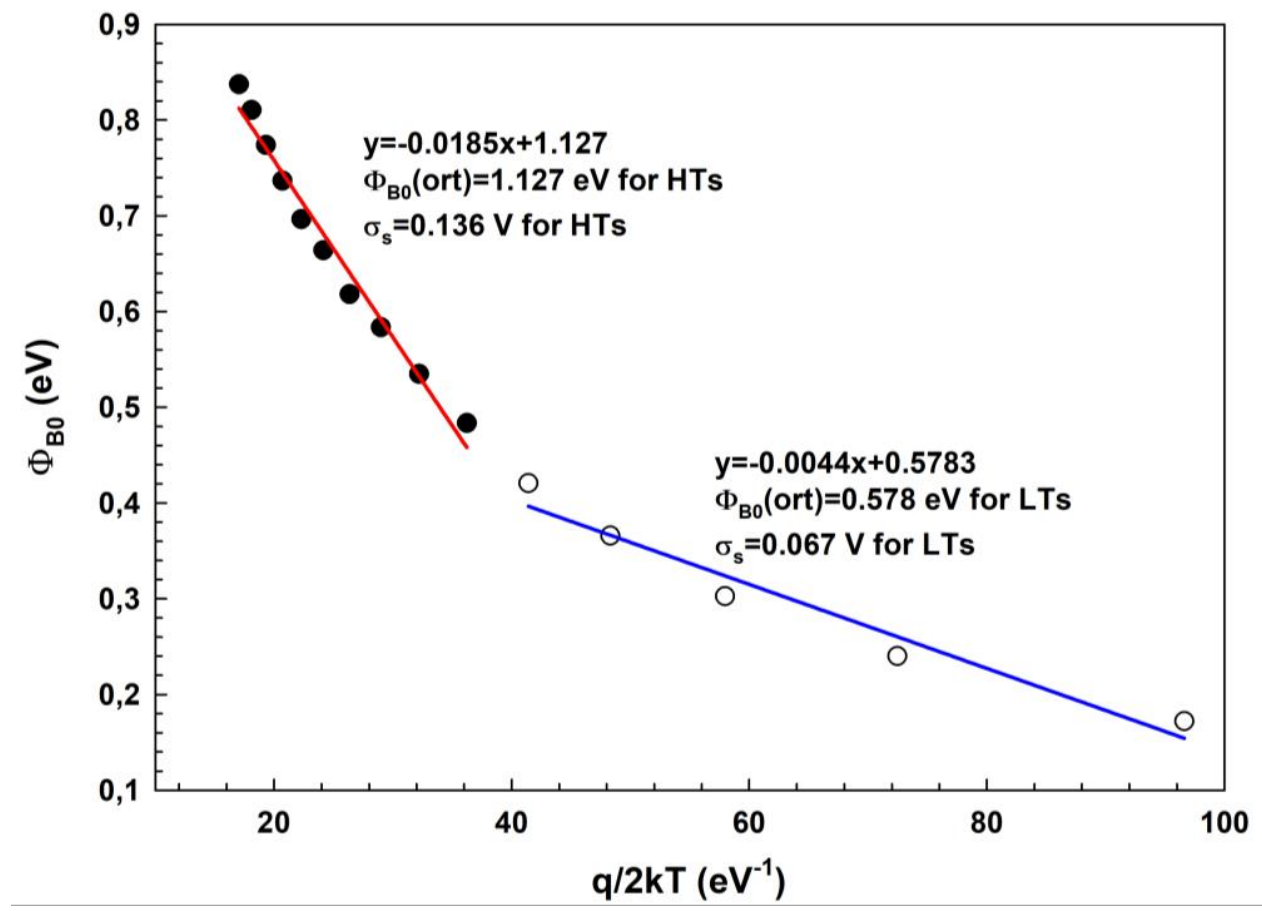

Fig. 10. The $\Phi_{\text {Bo }}$ vs $q / 2 k T$ plot of the Au/(nanocarbon-PVP)/n-Si SBD.

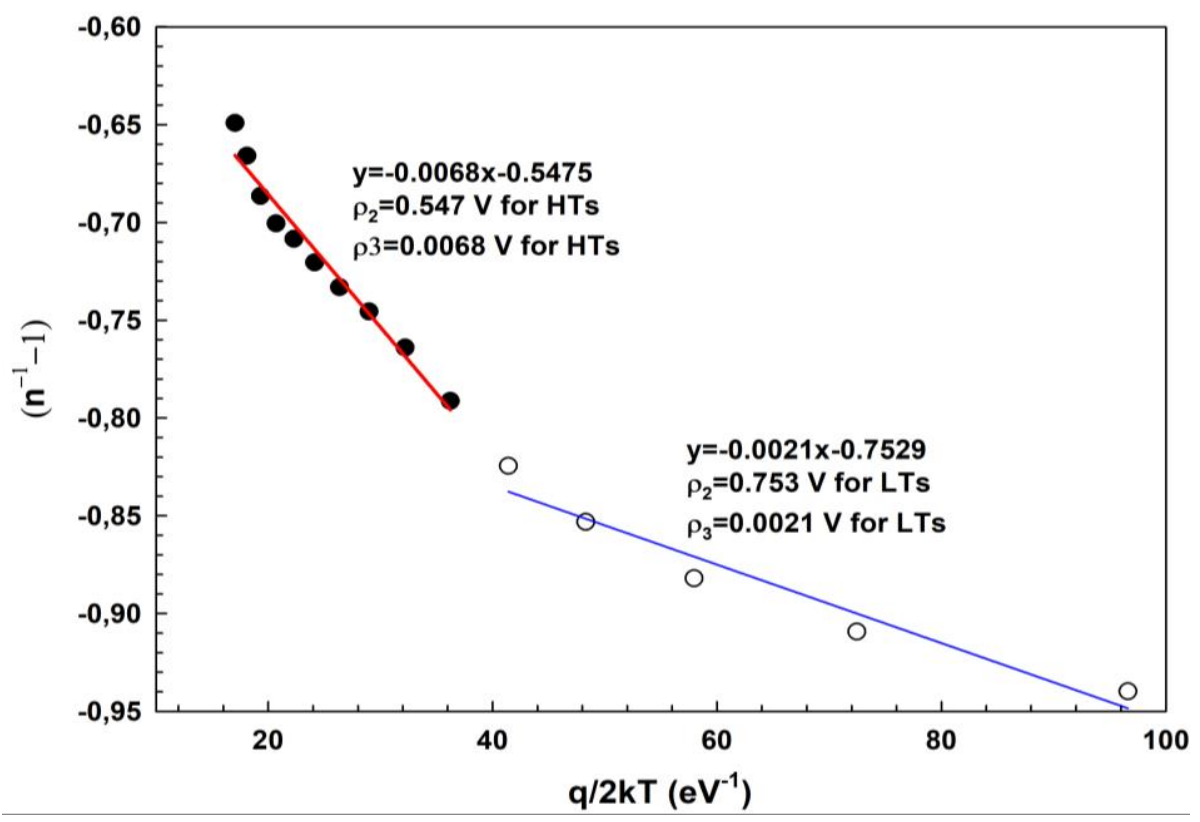

Fig. 11. The $\left(n^{-1}-1\right)$ vs $q / 2 k T$ plot of the Au/(nanocarbon-PVP)/n-Si SD. 
Now, by utilizing the values of $\sigma_{\text {so }}$ for moderate-high $(160-340 \mathrm{~K})$ and low $(60-140 \mathrm{~K})$ temperatures regimes, the conventional Richardson or Arsenious as a follow:

$$
\operatorname{Ln}\left(\frac{I_{0}}{T^{2}}\right)-\frac{1}{2}\left(\frac{q \sigma_{S 0}}{k T}\right)^{2}=\operatorname{Ln}\left(A A^{*}\right)-\frac{q \bar{\Phi}_{B 0}}{k T}
$$

In Fig. 10, the changed Richardson plot has two linear regimes with different slopes. Thus, by fitting Eq. 8, the $\bar{\Phi}_{\mathrm{Bo}}$ and $\mathrm{A}^{*}$ magnitudes for the Au/(nanocarbon-PVP)/n-Si SD were found the slope and intercept these plots as $1.126 \mathrm{eV}$ and $110.30 \mathrm{~A} / \mathrm{K}^{2} \mathrm{~cm}^{2}$ for moderate-high with 0.607 and $83.37 \mathrm{~A} / \mathrm{K}^{2} \mathrm{~cm}^{2}$ for low-temperatures respectively. $\mathrm{A}^{*}$ especially for moderatehigh temperature range is very close to its theoretical magnitude $112 \mathrm{~A} / \mathrm{K}^{2} \mathrm{~cm}^{2}$. As a result, the CTMs in the sample are governed by double GD of BH rather than tunneling mechanism. The mean magnitudes of $\bar{\Phi}_{\text {Bo }}$ extracted from Figs. 9, 10 and 13 are good agreement each other.

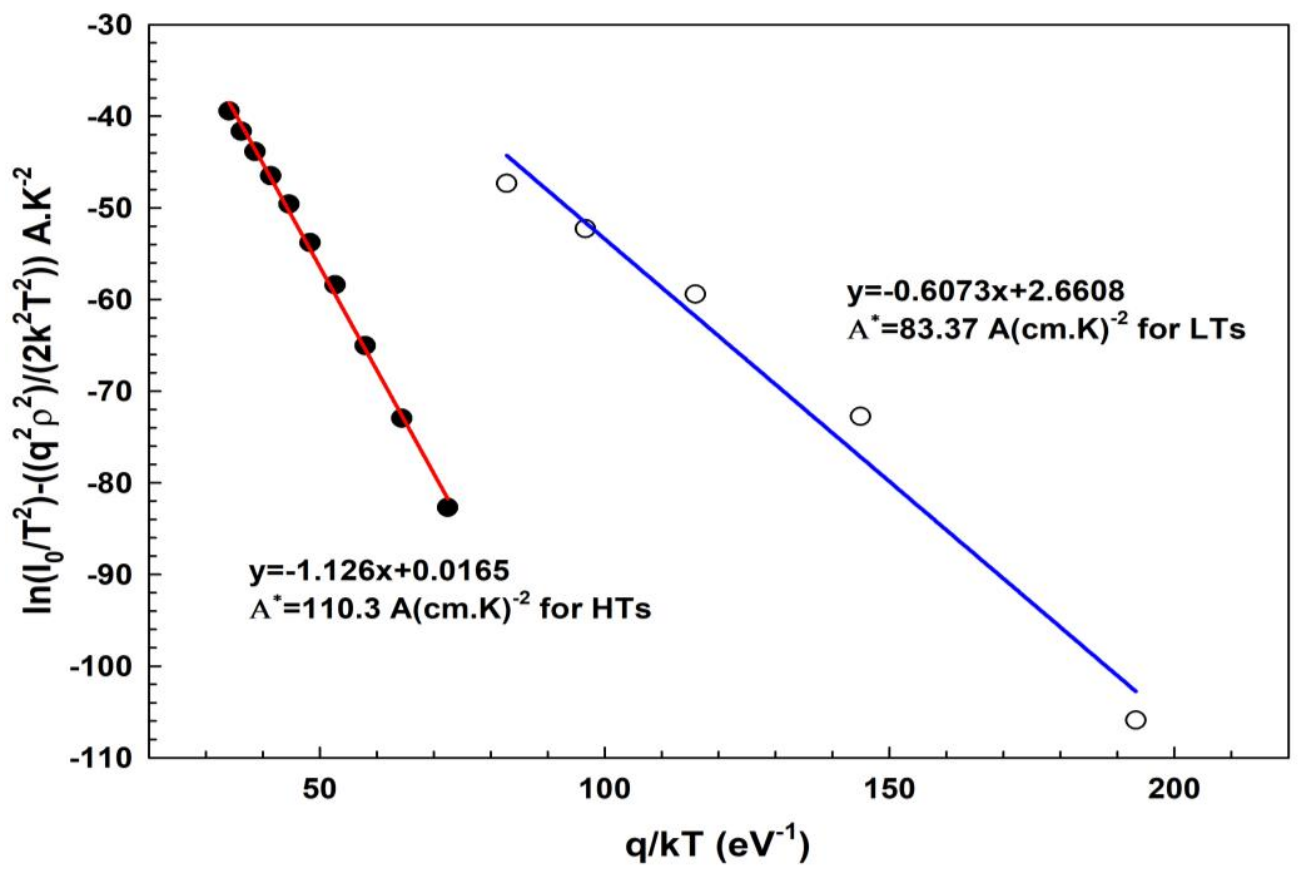

Fig 12. The modified Richardson/Arrhenius plot of the Au/(nanocarbon-PVP)/n-Si SD.

According to Card and Rhoderick [36] the energy associated with $\mathrm{N}_{\mathrm{ss}}$ can be successfully calculated from the forward I-V zone for each temperature, take account of the voltage dependence of the ideal factor $(\mathrm{n}(\mathrm{V}))$ and effective $\mathrm{BH}\left(\Phi_{\mathrm{e}}\right)$ utilizing the following formulas [36].

$$
\Phi_{e}=\Phi_{B O}+\beta\left(V-I R_{s}\right)=\Phi_{B O}+\left(1-\frac{1}{\mathrm{n}(V)}\right)\left(V-I R_{s}\right)
$$


$E c-E s s=q\left(\Phi_{e}-V\right)$

In Eq. $9, \beta\left(=\mathrm{d} \Phi_{\mathrm{e}} / \mathrm{dV}=1-1 / \mathrm{n}(\mathrm{V})\right)$ is the voltage coefficient of BH used in the place of the $\Phi_{\mathrm{Bo}}$. Thus, the $\mathrm{N}_{\mathrm{ss}}$ vs (Ec-Ess) was extracted from Eqs. 10 and 11 as follow [36]:

$\mathrm{N}_{\mathrm{ss}}(V)=\frac{1}{q}\left[\frac{\varepsilon_{i}}{d}(\mathrm{n}(V)-1)-\frac{\varepsilon_{s}}{W_{D}}\right]$

In Fig. 11 is an exponential growth of the $\mathrm{N}_{\mathrm{ss}}$ from mid-gap of Si towards the bottom of $\mathrm{E}_{\mathrm{c}}$ for each temperature and the mean value of them altered from the $4.9 \times 10^{13} \mathrm{eV}^{-1} \mathrm{~cm}^{-2}$ at $60 \mathrm{~K}$ to $0.95 \times 10^{12} \mathrm{eV}^{-1} \mathrm{~cm}^{-2}$ at $340 \mathrm{~K}$ which are reasonable for the MPS type SD. Changes in this magnitude and their positioning with temperature can be associated with reordering and restructuring under the effects of electric field and temperature.

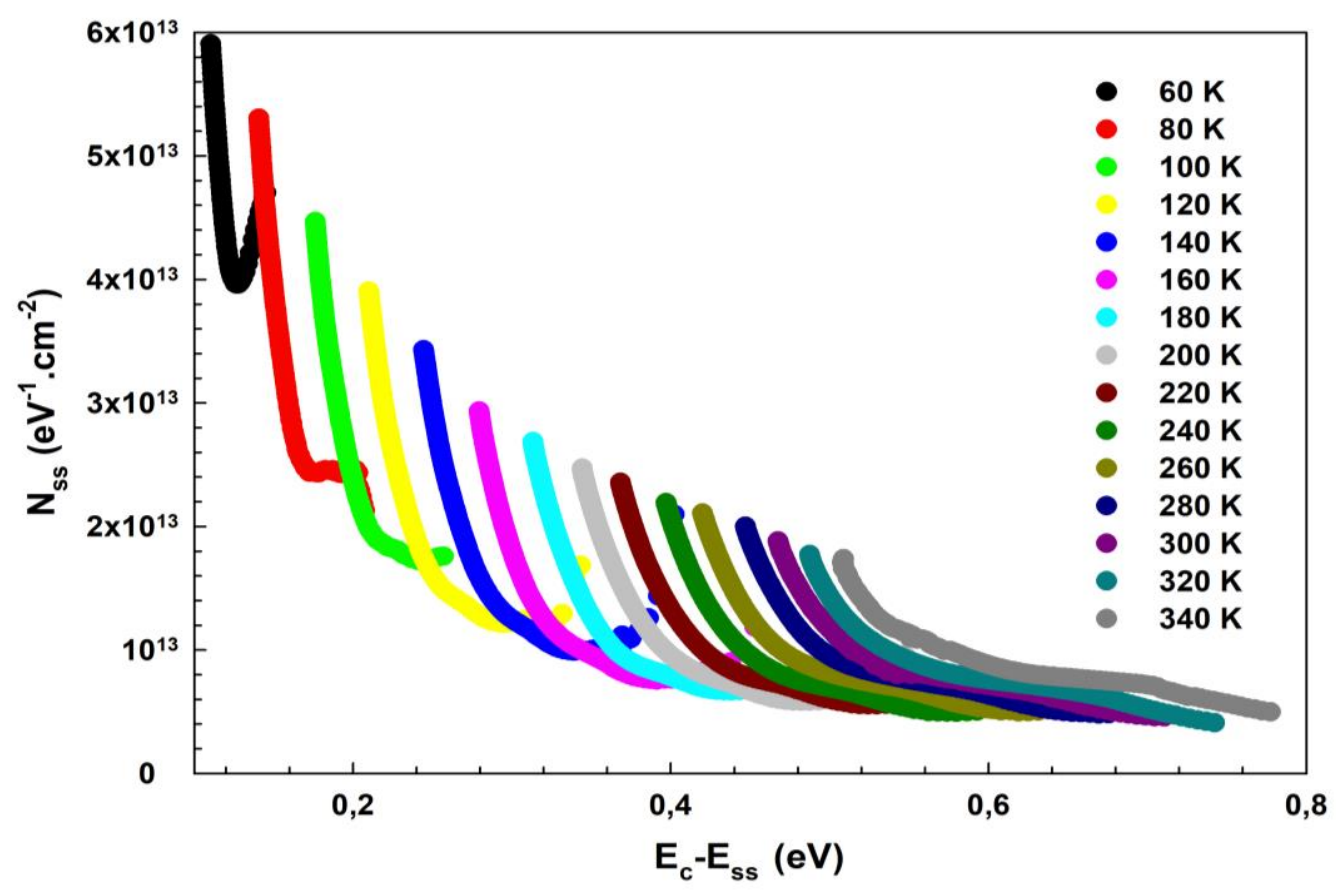

Fig. 13. The $\mathrm{N}_{\mathrm{ss}}-\left(\mathrm{E}_{\mathrm{c}}-\mathrm{E}_{\mathrm{ss}}\right)$ plots of the $\mathrm{Au} /($ nanocarbon-PVP)/n-Si SD for various temperatures.

\section{Conclusions}

In this working, the current-voltage-temperature (I-V-T) properties of the fabricated $\mathrm{Au} /($ nanocarbon-PVP)/n-Si SDs have been examined in temperature (60-340 K) and bias voltage $( \pm 3 \mathrm{~V})$. All electrical magnitudes of them, for instance, $I_{o}, n, \Phi_{\mathrm{Bo}}, R_{\mathrm{s}}, R_{\mathrm{sh}}$ and $\mathrm{N}_{\mathrm{ss}}$ have obtained a function of temperature and the changes of them with temperature become more distinctive 
especial with lowing temperature and moderate temperatures. The magnitude of $\Phi_{\text {Bo increased }}$ from $0.173 \mathrm{eV}$ to $0.837 \mathrm{eV}$, while the $\mathrm{n}$ value decreased from 16.60 to 2.85 with the temperature rising from $60 \mathrm{~K}$ to $340 \mathrm{~K}$. Especially, the higher value of $\mathrm{n}$ with lowing temperature is attributed to inhomogeneous barriers rather than the presence of the organic intermediate layer and Nss. This positive temperature coefficient of $\Phi_{\text {Во }}$ is not compatible with Si bandgap or ideal diode. The traditional Richardson plot also deviated from the linearity with lowing temperature $(\mathrm{T} \leq 140$ $\mathrm{K}$ ), and the value of $\mathrm{A}^{*}$ was considerably lower than its theoretical magnitude. To explain this unexpected behavior of $\Phi_{\mathrm{B}}$ and $\mathrm{A}^{*}$, graphs of $\Phi_{\mathrm{Bo}}$ and $\mathrm{n}^{*}$ against the $\mathrm{BH}$ and $\mathrm{n} / \mathrm{q} / 2 \mathrm{kT}$ domains were plotted to obtain a proof of the GD of the BH values on the diode domain. These two plots show two linear fits of rage with different slopes and intercept between 60-140 K and 160-340K, respectively. By utilizing the obtained values of $\sigma_{\text {so }}$ from the intercept of the $\Phi_{\text {Bo }}$ vs $q / 2 \mathrm{kT}$ plots, the conventional Richardson was modified. Thereafter, the slope of $\bar{\Phi}_{\mathrm{Bo}}$ and $\mathrm{A}^{*}$ values for $\mathrm{Au} /$ (nanocarbon-PVP)/n-Si SD was found and cut this graph to $1.126 \mathrm{eV}$ and $110.30 \mathrm{~A} / \mathrm{K}^{2} \mathrm{~cm}^{2}$ for the temperature range $160-340 \mathrm{~K}$. and 0.607 and $83.37 \mathrm{~A} / \mathrm{K}^{2} \mathrm{~cm}^{2}$ for $60-140 \mathrm{~K}$, respectively. $\mathrm{A}^{*}$ magnitude is very close to the theoretical $112 \mathrm{~A} / \mathrm{K}^{2} \mathrm{~cm}^{2}$ magnitude, especially for the mediumhigh temperature range. Consequently, the CTMs in the Au/(nanocarbon-PVP)/n-Si SD are governed by double GD of $\mathrm{BH}$ rather than tunneling mechanism. The $\mathrm{N}_{\mathrm{ss}} \mathrm{vs}\left(\mathrm{E}_{\mathrm{c}}-\mathrm{E}_{\mathrm{ss}}\right)$ profile for each temperature was also calculated from the forward bias I-V data by taking into account voltage-dependent of $\mathrm{n}$ and effective $\mathrm{BH}$. This mean value of them changed from the $4.9 \times 10^{13}$ $\mathrm{eV}^{-1} \mathrm{~cm}^{-2}$ at $60 \mathrm{~K}$ to $0.95 \times 10^{12} \mathrm{eV}^{-1} \mathrm{~cm}^{-2}$ at $340 \mathrm{~K}$ which are reasonable for the MPS type SD. Changes in this magnitude and their positioning with temperature can be associated with reordering and restructuring under the effects of electric field and temperature. 


\section{References:}

1. J. P. Sullivan, R. T. Tung, M. R. Pinto, and W. R. Graham, Journal of Applied Physics 70, 7403 (1991).

2. W. Mönch, Journal of Vacuum Science \& Technology B: Microelectronics and Nanometer Structures 17, 1867 (1999).

3. Ş. Altındal, A. Tataroğlu, and İ. Dökme, Solar Energy Materials and Solar Cells 85, 345 (2005).

4. O. Dupré, R. Vaillon, and M. A. Green, Solar Energy Materials and Solar Cells 140, 92 (2015).

5. S. Chand and J. Kumar, Applied Physics A: Materials Science and Processing 65, 497 (1997).

6. R. T. Tung, Physical Review B 45, 13509 (1992).

7. J. H. Werner and H. H. Güttler, Journal of Applied Physics 69, 1522 (1991).

8. J. Osvald and Z. J. Horváth, Applied Surface Science 234, 349 (2004).

9. Z. J. Horváth, Solid-State Electronics 39, 176 (1996).

10. S. Alialy, Ş. Altındal, E. E. Tanrıkulu, and D. E. Yıldız, Journal of Applied Physics 116, 083709 (2014).

11. E. Arslan, Ş. Altindal, S. Özçelik, and E. Ozbay, Semiconductor Science and Technology 24, 075003 (2009).

12. E. Özavc1, S. Demirezen, U. Aydemir, and Ş. Altındal, Sensors and Actuators A: Physical 194, 259 (2013).

13. F. A. Padovani and R. Stratton, Solid-State Electron 9, 695 (1966).

14. B. L. Sharma, Metal-Semiconductor Schottky Barrier Junctions and Their Applications (Plenum Press, New York, 1984).

15. S. M. Sze, Physics of Semiconductor Devices, 2nd ed. (Willey, New York, 1981).

16. R. F. Schmitsdorf, T. U. Kampen, and W. Mönch, Surface Science 324, 249 (1995).

17. Ç. Güçlü, A. F. Özdemir, and Ş. Altindal, Applied Physics A: Materials Science and Processing 122, 1032 (2016).

18. S. Altındal Yerişkin, Journal of Materials Science: Materials in Electronics 30, 17032 (2019).

19. İ. Taşçıŏlu, S. O. Tan, F. Yakuphanoğlu, and Ş. Altındal, Journal of Electronic Materials 47, 6059 (2018).

20. H. Durmuş, M. Yıldırım, and Ş. Altındal, Journal of Materials Science: Materials in Electronics 30, 9029 (2019).

21. B. P. Lakshmi, M. S. P. Reddy, A. A. Kumar, and V. R. Reddy, Current Applied Physics 12, 765 (2012).

22. R. T. Tung, Materials Science and Engineering: R: Reports 35, 1 (2001).

23. S. Chand and J. Kumar, Applied Physics A 178, 171 (1996).

24. A. Karabulut, Bulletin of Materials Science 42, 1 (2019).

25. A. Kaya, O. Sevgili, and S. Altindal, International Journal of Modern Physics B 28, (2014). 26. S. Boughdachi, Y. Badali, Y. Azizian-Kalandaragh, and Ş. Altındal, Journal of Electronic Materials 47, 6945 (2018).

27. P. Singh, S. N. Singh, M. Lal, and M. Husain, Solar Energy Materials and Solar Cells 92 , 1611 (2008).

28. Y. P. Song, R. L. Van Meirhaeghe, W. H. Laflère, and F. Cardon, Solid-State Electronics 29, 633 (1986).

29. Y. Munikrishna Reddy, R. Padmasuvarna, T. Lakshmi Narasappa, R. Padma, and V.

Rajagopal Reddy, Indian Journal of Physics 89, 1161 (2015).

30. M. K. Hudait, P. Venkateswarlu, and S. B. Krupanidhi, Solid-State Electronics 45, 133 
(2001).

31. S. Altındal Yerişkin, M. Balbaşı, and S. Demirezen, Indian Journal of Physics 91, 421 (2017).

32. Ö. Vural, N. Yıldırım, Ş. Altındal, and A. Türüt, Synthetic Metals 157, 679 (2007).

33. M. H. Al-Dharob, H. E. Lapa, A. Kökce, A. F. Özdemir, D. A. Aldemir, and Ş. Altındal, Materials Science in Semiconductor Processing 85, 98 (2018).

34. V. Rajagopal Reddy, V. Manjunath, V. Janardhanam, C. H. Leem, and C. J. Choi, Journal of Electronic Materials 44, 549 (2015).

35. Ö. Sevgili, S. Yılmaz, Ş. Altındal, E. Bacaksız, and Ç. Bilkan, Proceedings of the National Academy of Sciences India Section A - Physical Sciences 87, 409 (2017).

36. H. C. Card and E. H. Rhoderick, Journal of Physics D: Applied Physics 4, 1589 (1971).

37. Ş. Altındal, Ö. Sevgili, and Y. Azizian-Kalandaragh, Journal of Materials Science:

Materials in Electronics 30, 9273 (2019).

38. H. G. Çetinkaya, Ö. Sevgili, and Ş. Altındal, Physica B: Condensed Matter 560, 91 (2019).

39. G. E. . Demir, İ. . Yücedăg, and S. A. Yerişkin, Journal of Nanoelectronics and

Optoelectronics, 14, 653 (2019).

40. A. Büyükbaş Uluşan, A. Tataroğlu, Y. Azizian-Kalandaragh, and Ş. Altındal, Journal of Materials Science: Materials in Electronics 29, 159 (2018).

41. Ç. Bilkan, Y. Badali, S. Fotouhi-Shablou, Y. Azizian-Kalandaragh, and Ş. Altındal, Applied Physics A: Materials Science and Processing 123, 1 (2017).

42. Ç. G. Türk, S. O. Tan, Ş. Altındal, and B. İnem, Physica B: Condensed Matter 582, 411979 (2020). 
Figures

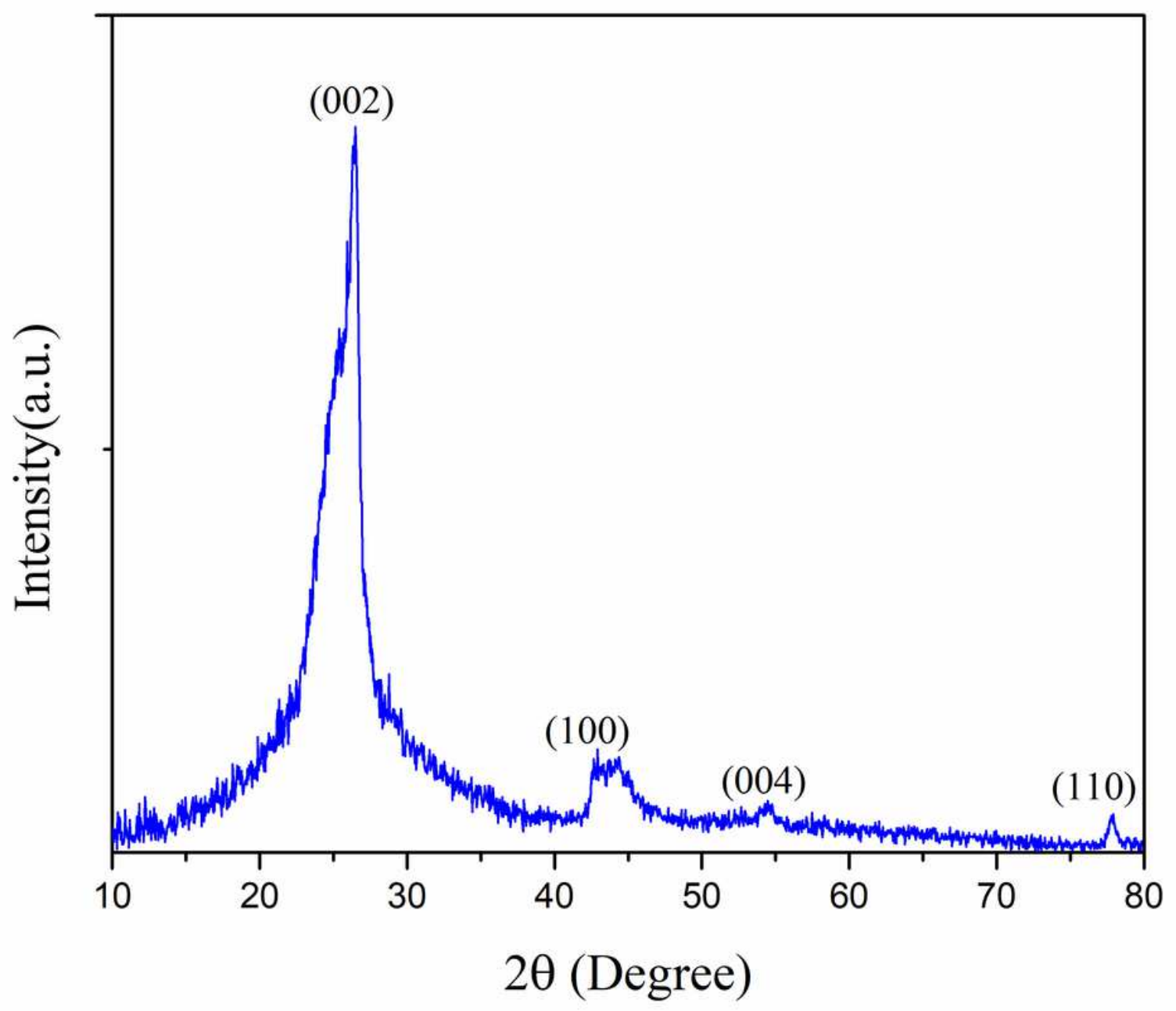

Figure 1

The XRD patterns of nanocarbon. 

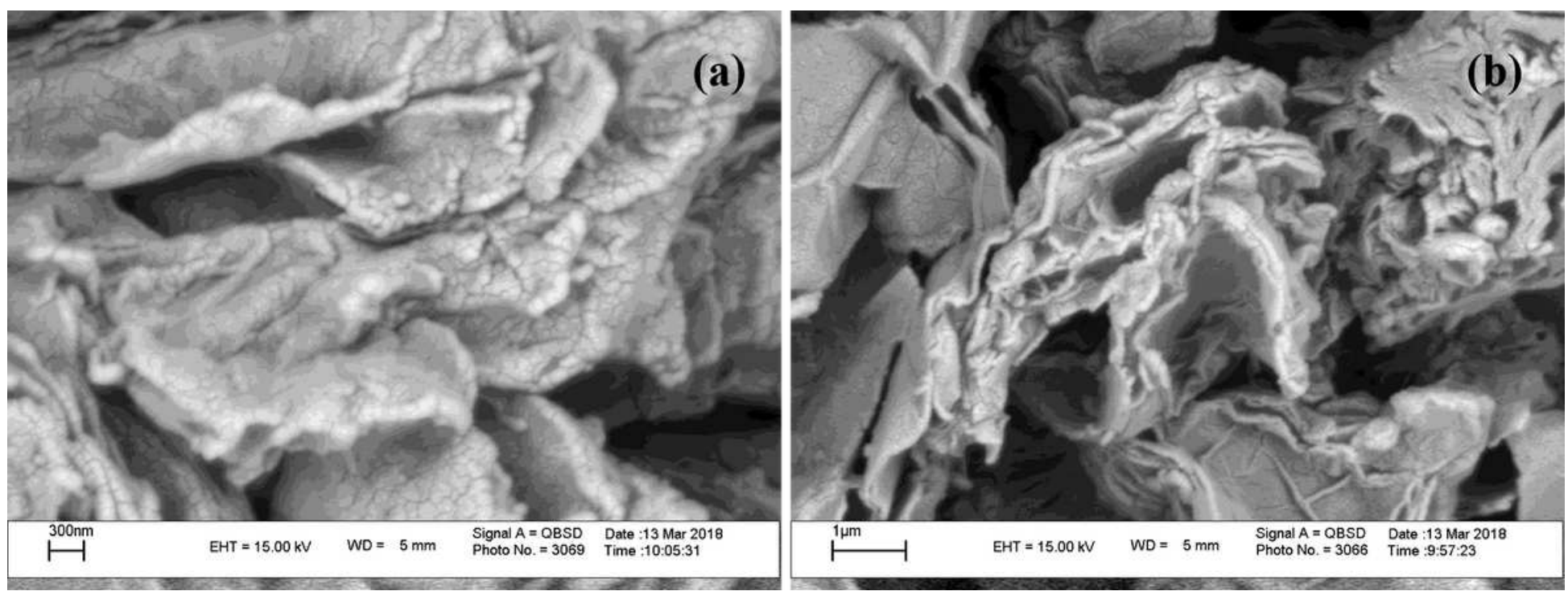

Figure 2

SEM images of nanocarbon: a) $50 \mathrm{kx}, \mathrm{b}) 30 \mathrm{kx}$. 


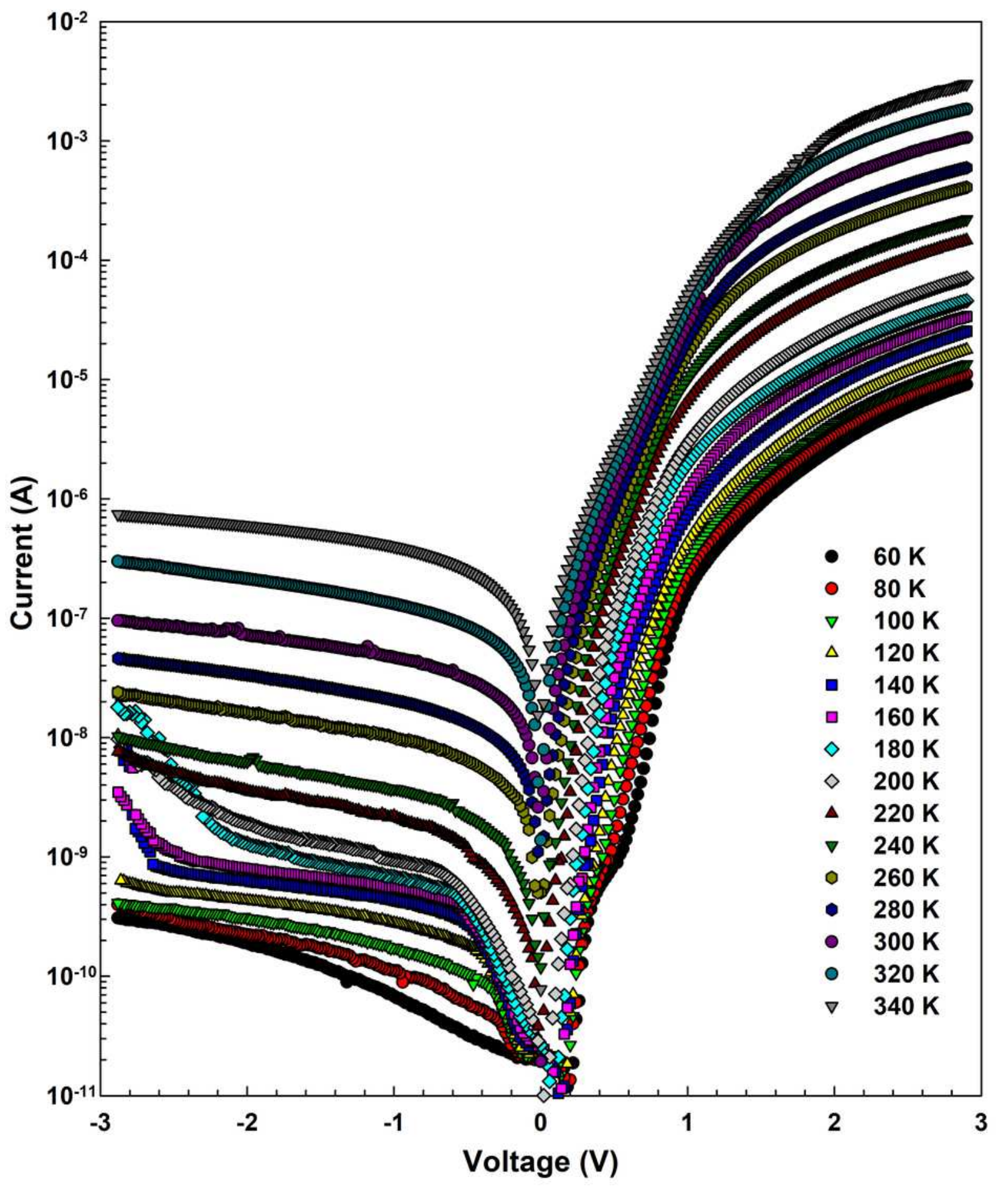

Figure 3

The I-V-T characteristics of the Au/(nanocarbon-PVP)/n-Si SD. 


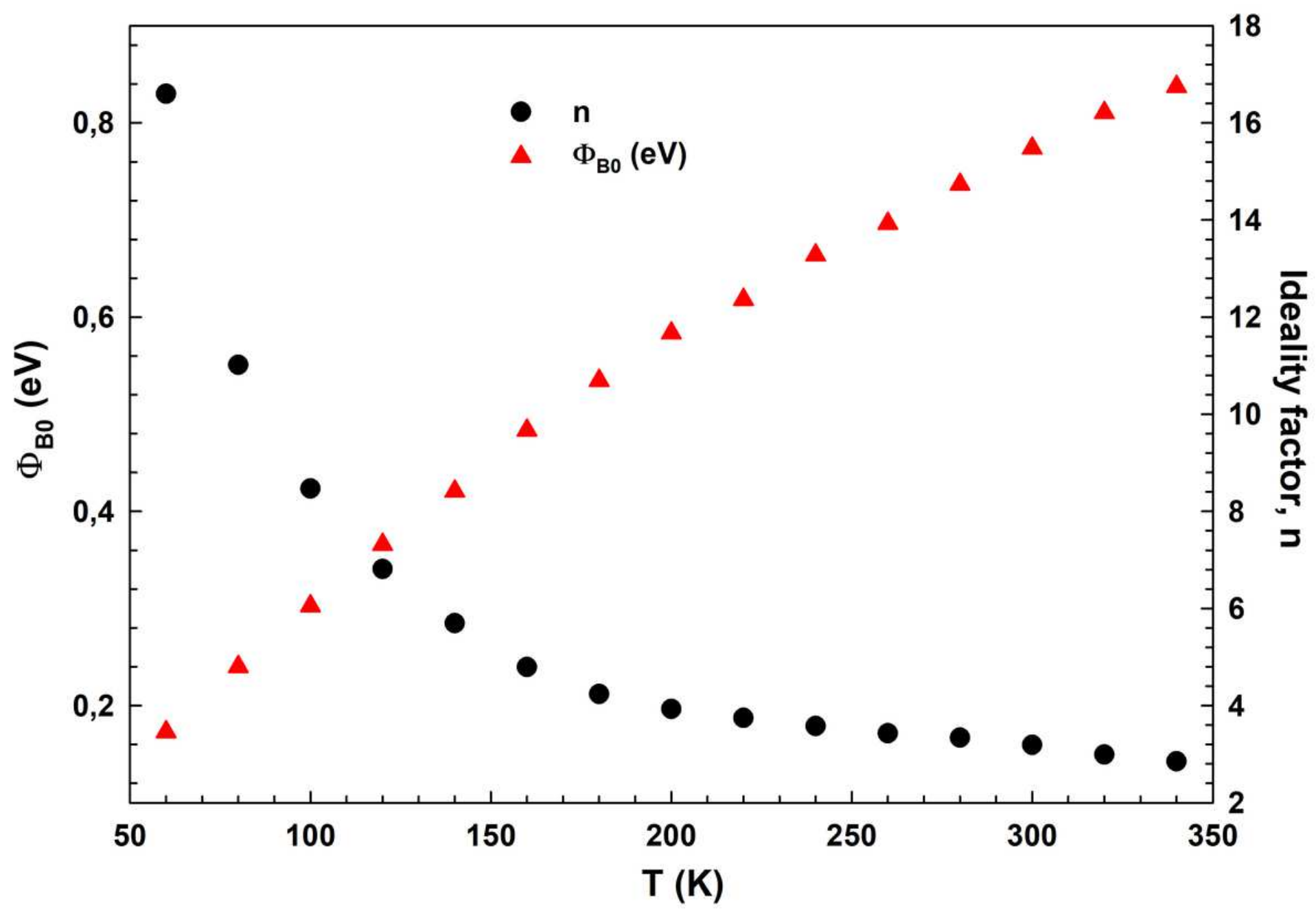

Figure 4

The changes in $\mathrm{BH}$ and $\mathrm{n}$ with temperature in $\mathrm{Au} /($ nanocarbon-PVP)/n-Si SD. 


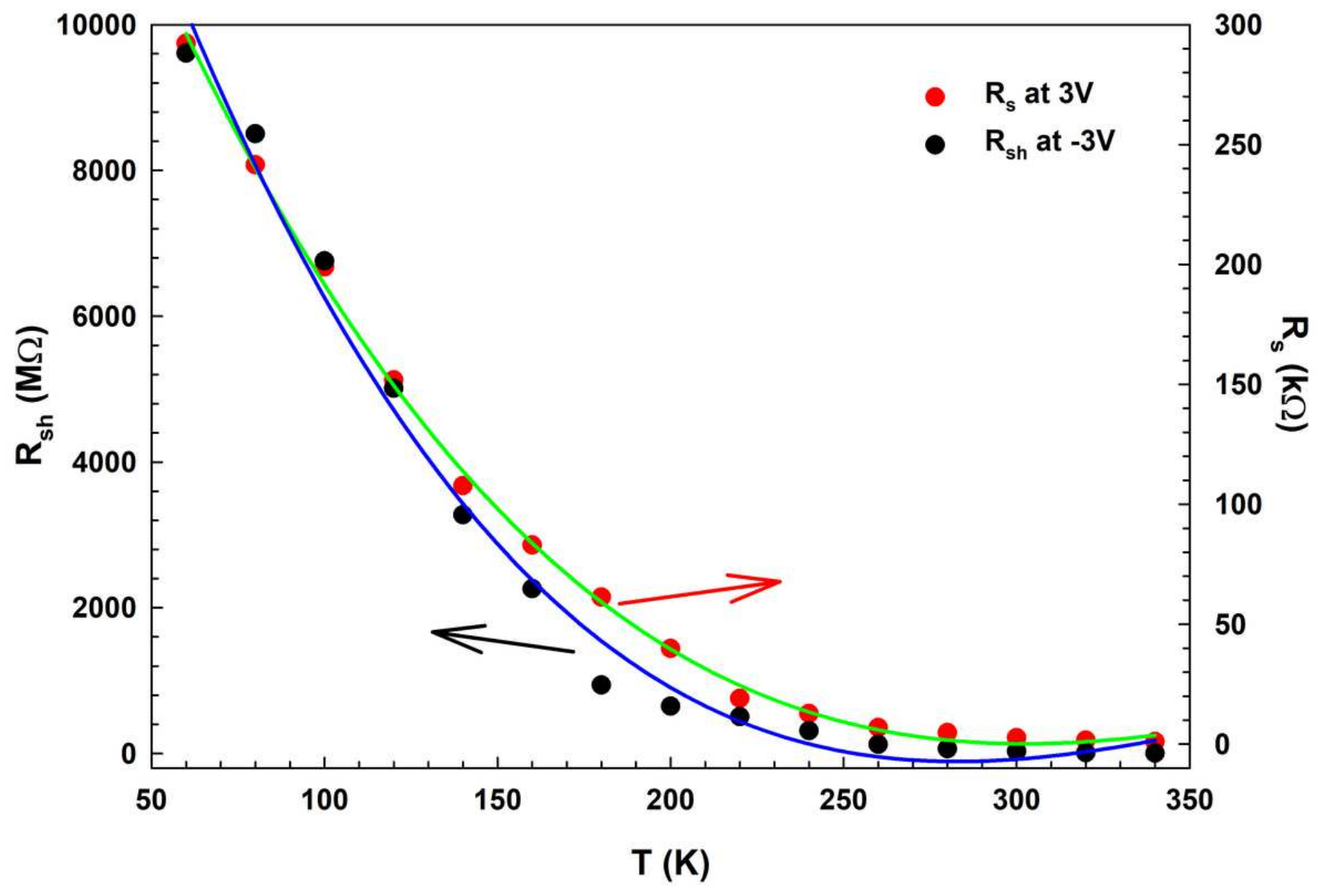

Figure 5

The changes in Rs and Rsh with temperature in Au/(nanocarbon-PVP)/n-Si SD. 


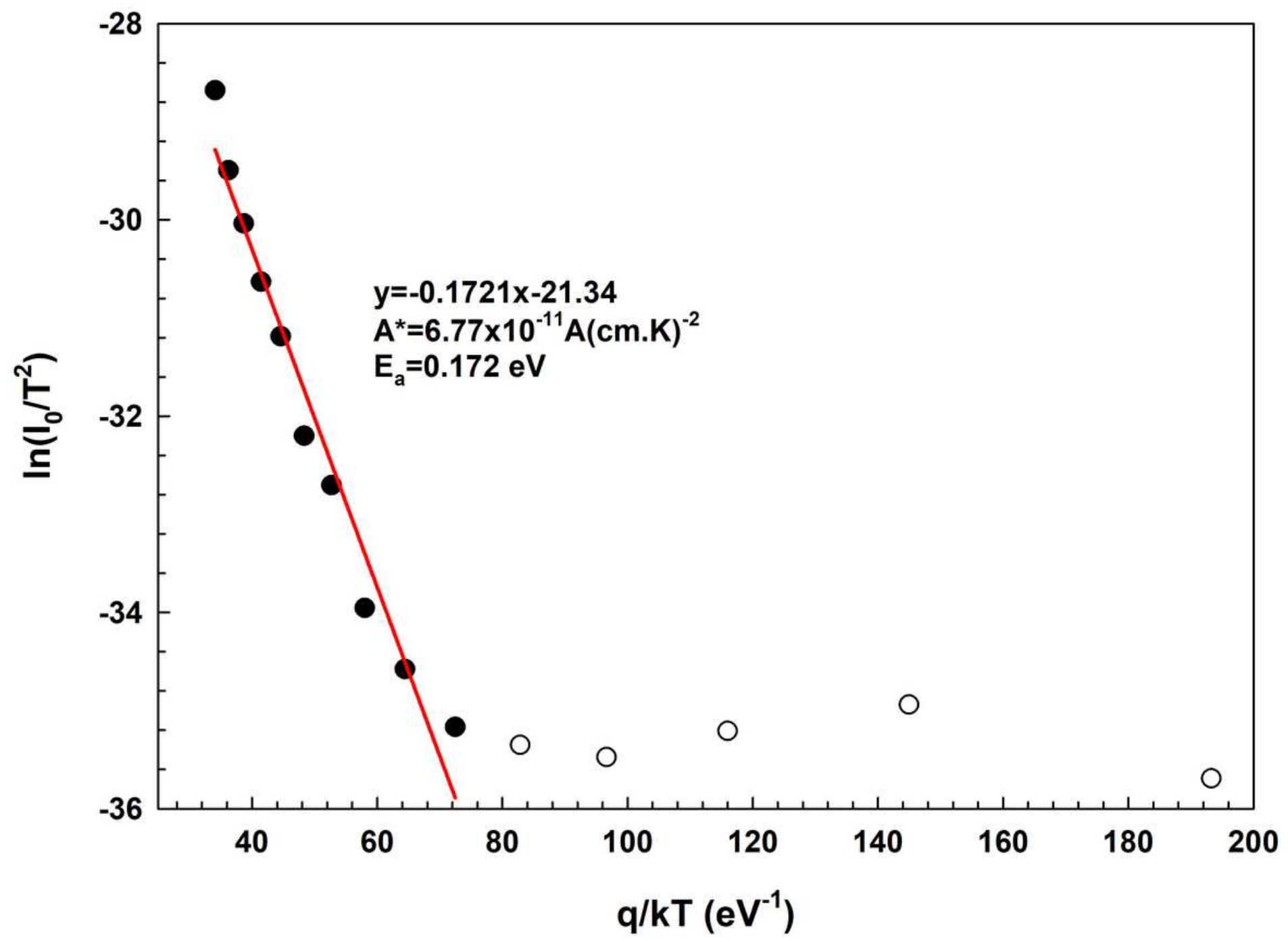

Figure 6

The conventional Richardson/Arrhenius plot of the Au/(nanocarbon-PVP)/n-Si SD. 


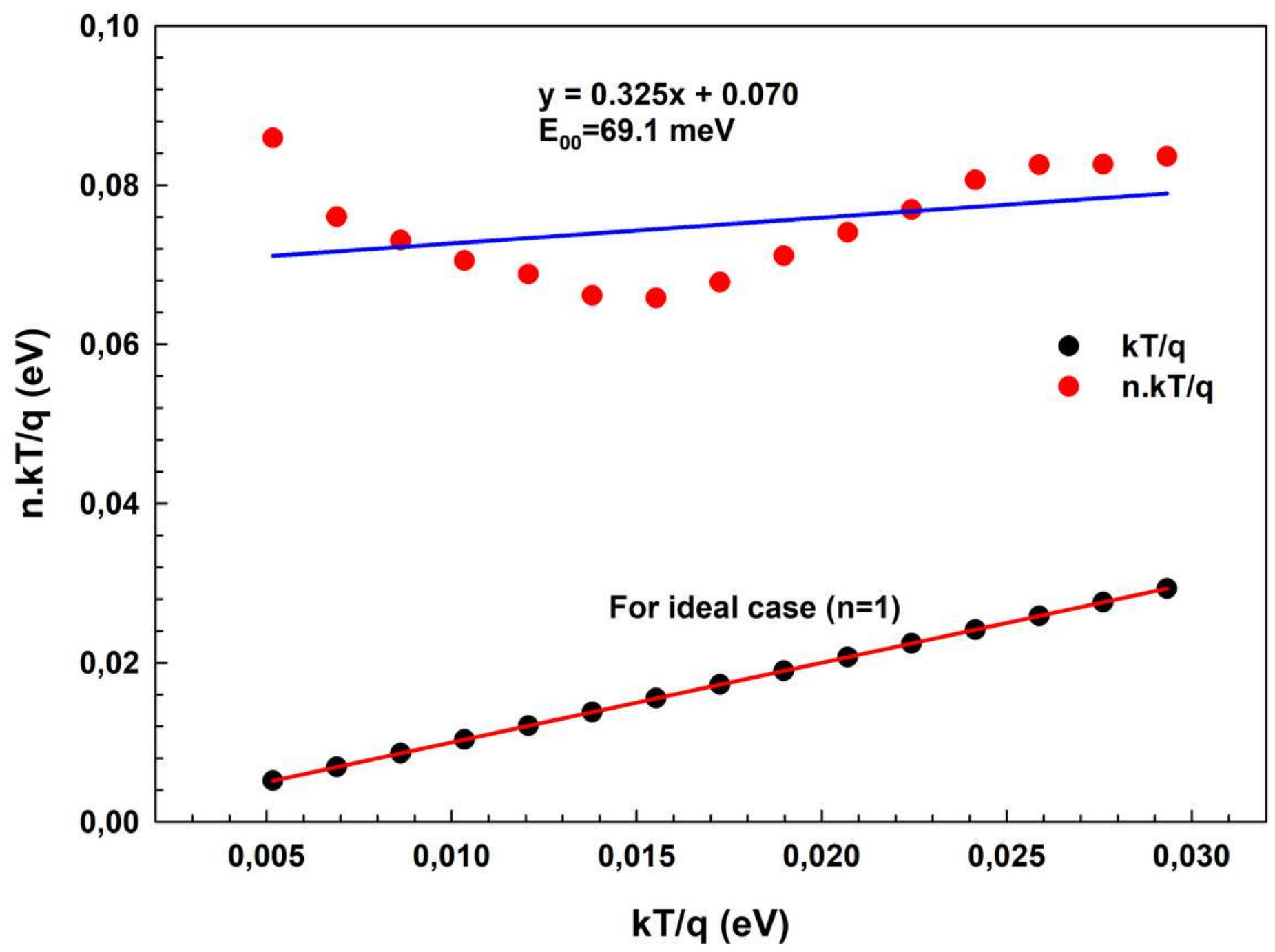

Figure 7

The $n k T / q$ vs kT/q plot of the Au/(nanocarbon-PVP)/n-Si SD. 


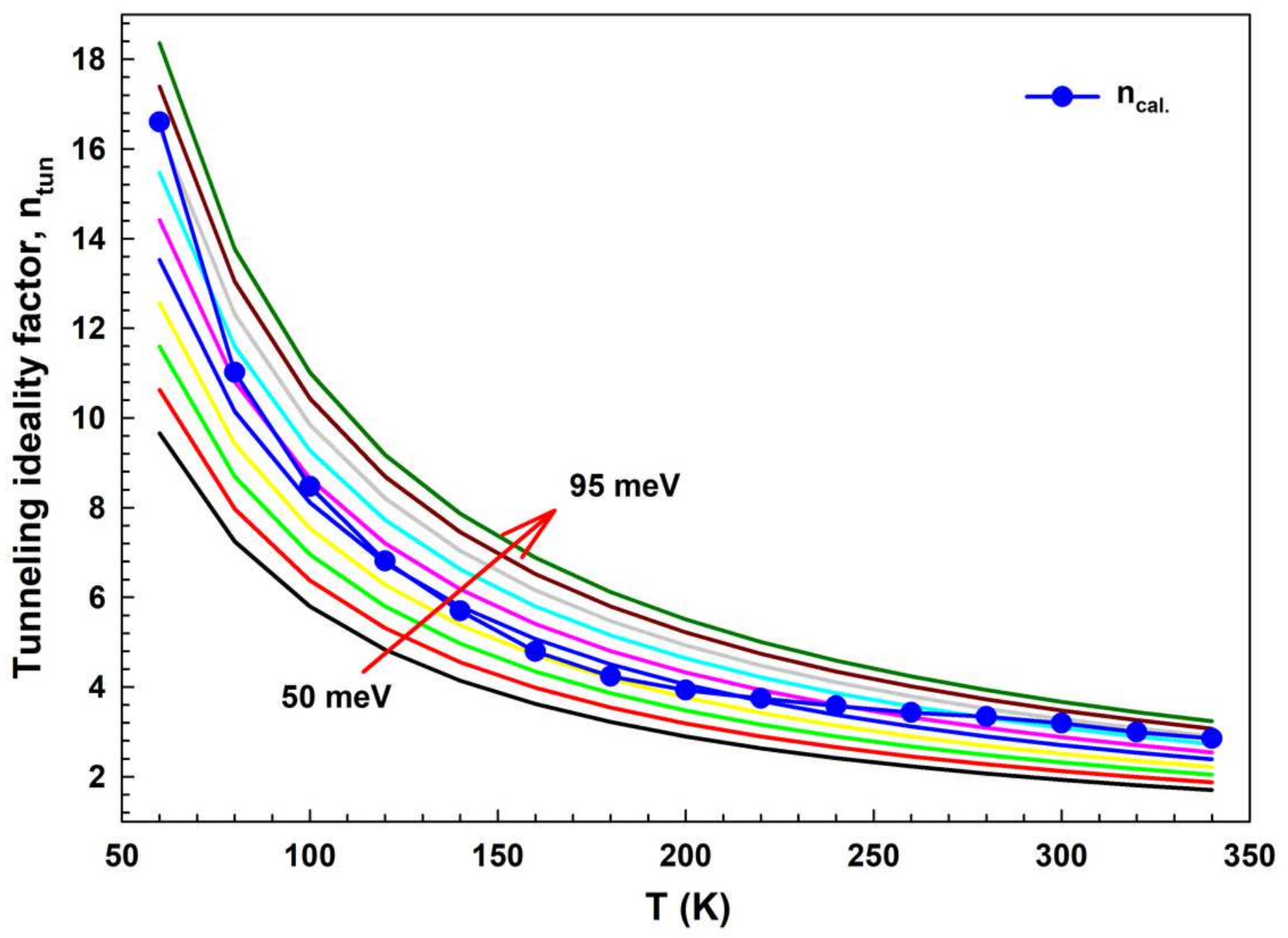

Figure 8

The ntun vs T plot of the Au/(nanocarbon-PVP)/n-Si SD far various Eoo. 


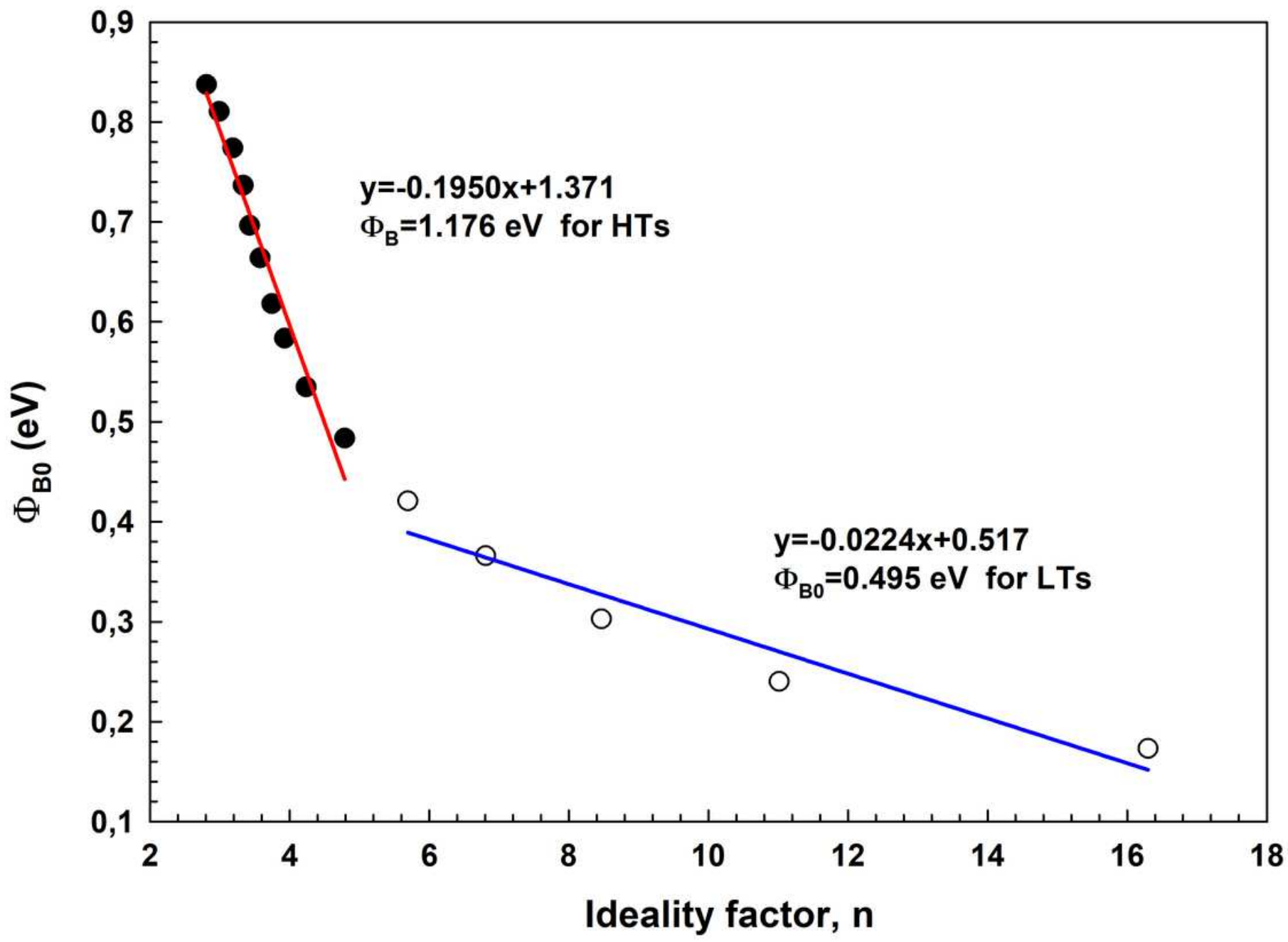

Figure 9

Temperature-dependent $\Phi$ Bo vs $n$ plot of the Au/(nanocarbon-PVP)/n-Si SD. 


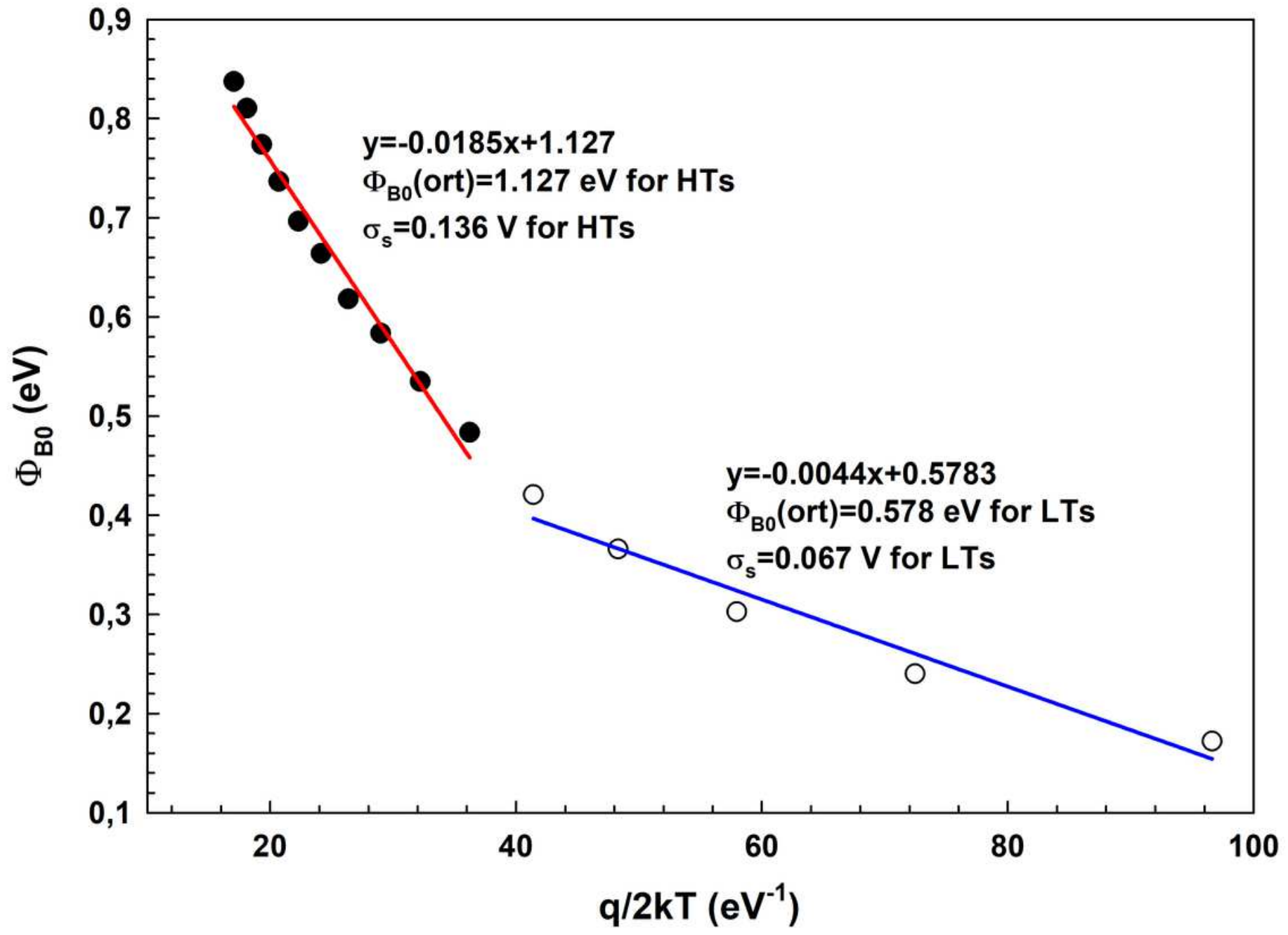

Figure 10

The $\Phi$ Bo vs q/2kT plot of the Au/(nanocarbon-PVP)/n-Si SBD. 


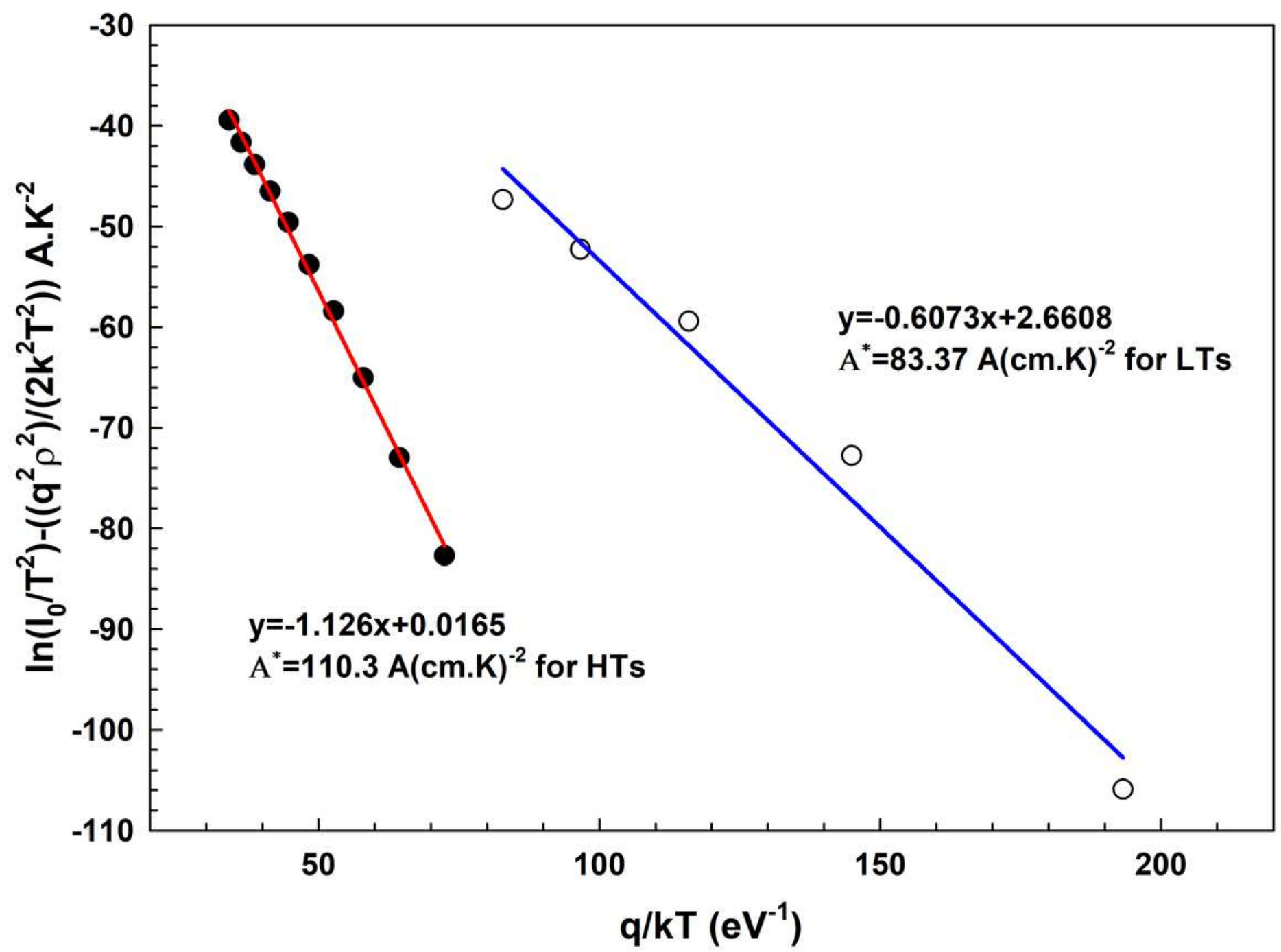

Figure 12

The modified Richardson/Arrhenius plot of the Au/(nanocarbon-PVP)/n-Si SD. 


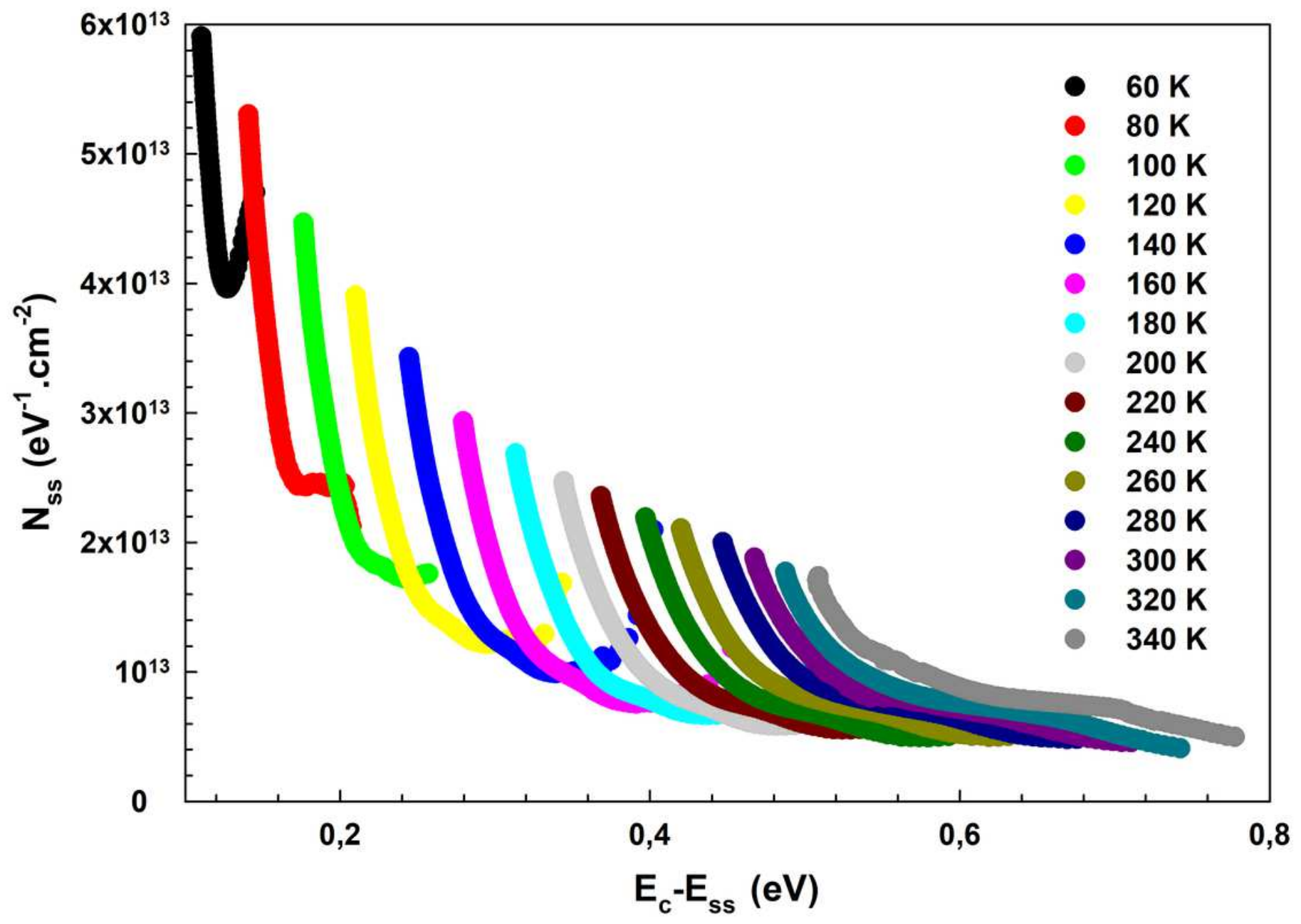

Figure 13

The Nss-(Ec-Ess) plots of the Au/(nanocarbon-PVP)/n-Si SD for various temperatures 